\title{
PLURALISMO RELIGIOSO, EDUCACIÓN Y CIUDADANÍA $^{1}$
}

\section{Cristián Parker G.*}

\begin{abstract}
Resumen: Este artículo describe las formas peculiares que adquiere el cambio religioso, tanto a nivel de las adhesiones a nuevos movimientos religiosos como en las creencias religiosas en Chile. Este trabajo analiza la manera en que el factor educacional interviene en las tendencias hacia la pluralización religiosa. También se exploran las posibles consecuencias que puedan tener las manifestaciones concretas del cambio religioso en la cultura política de Chile.
\end{abstract}

Palabras clave: cambio religioso; pluralización religiosa; creencias religiosas; Chile.

\section{Introducción}

América Latina está siendo transformada bajo diversos aspectos y el cambio religioso experimentado en los últimos treinta años nos está ofreciendo un panorama cultural y social muy característico en la primera década de este siglo.

En efecto, al final de la década de los 80 se afirmaba que América Latina se volvía protestante (Martin, 1990; Stoll, 1990), aún cuando la evolución reciente no nos indica que estemos avanzando en esa dirección, sino más bien hacia el pluralismo religioso creciente. ¿Qué características adquiere el pluralismo religioso actual y cómo se pueden apreciar las consecuencias de ese cambio en el campo sociopolítico?

\footnotetext{
* Doctor en Sociología, Instituto de Estudios Avanzados, Universidad de Santiago de Chile. Artigo recebido em 5 maio 2008 e aprovado em 30 jun. 2008.
} 
En este artículo exploraremos las peculiares formas que adquiere el cambio religioso, sobre todo a nivel de adhesiones y creencias religiosas y su impacto en la arena cívica y política de los países latinoamericanos. Basaremos nuestro análisis en datos obtenidos de diversos estudios realizados en Chile y compararemos dicha información con evidencia disponible de estudios internacionales.

Buscando factores que intervienen en el cambio socioreligioso que mencionamos, nos hemos encontrado con el factor educacional por lo que revisaremos la información disponible en función de posibles explicaciones, al mismo tiempo que de argumentaciones que posibiliten generalizaciones predictivas acerca de estos cambios.

\section{Pluralismo religioso creciente}

Chile y el continente latinoamericano están pasando de haber sido "un país/continente católico" a ser un país/continente religiosamente pluralista (Parker, 2005). Crecientes textos nos hablan de la "diversidad religiosa" en los más variados países como Brasil (Teixeira y Menezes, 2006), Argentina (Forni, Mallimaci y Cárdenas, 2003), México (De la Torre y Gutiérrez, 2007). Una realidad que para Chile ya habíamos estudiado en los años 19941995 (Parker, 1996).

Luego de un crecimiento explosivo en la segunda década del siglo XX, en la primera década del siglo XXI el crecimiento de las iglesias evangélicas se ha reducido, sigue incrementándose en Centroamérica pero a un ritmo más lento y en algunos países de Sudamérica, incluso en algunos casos, se ha detenido. No puede mantenerse, por ello, que Chile o Latinoamérica se hayan vuelto "protestantes". Todavía hay una mayoría católica que bordea el 70\% 
de la población, pero ya no es una proporción superior al 92\% como fuese a principios del siglo XX, por lo que el pluralismo religioso actual es evidente.

\section{¿Cómo se explican estos cambios?}

La importancia de la religión en el contexto de los procesos de modernización y la diversificación de expresiones religiosas no es exclusivamente debida a los nuevos predicadores evangélicos y la influencia creciente de los pentecostales. Otros factores culturales profundos están envueltos y están influyendo en el nuevo panorama del pluralismo religioso.

En otro trabajo hemos analizado varios de estos factores culturales (Parker, 2003) que inciden en el cambio religioso:

- la cultura del consumismo promovida por el mercado y la nueva economía;

- los medios de comunicación de masa y la revolución en las comunicaciones y la electrónica;

- los profundos cambios en el campo educativo; y

- la renovación de los movimientos sociales y étnicos.

La gran consecuencia es que el creyente ya no reproduce las formas religiosas convencionales recibidas de sus padres.

De estos factores, el papel de la educación y los cambios de mentalidad que introducen deben ser considerados como principales en el proceso que conduce hacia el pluralismo religioso creciente ${ }^{2}$.

La educación moderna permite que el sujeto entre en contacto con un horizonte cultural más amplio, con estilos de vida diversos, e introduce en él una apreciación crítica de las cosas que tiende a 
cuestionar la tradición moral y los dogmas. Es más, niveles superiores de alternativas educativas ayudan a redefinir los modelos culturales y dan lugar a la sociedad pluricultural.

Las reformas educativas latinoamericanas y la modernización neoliberal en la educación de las últimas décadas bajo la guía del Banco Mundial ${ }^{3}$ han introducido una racionalización diferente en las escuelas y en la gestión educativa y han diversificado la oferta educativa. Ellas también han introducido una cultura más liberal. Y la liberalización cultural ha facilitado la aceptación de mensajes, creencias y rituales heterodoxos y una cierta desconfianza hacia las instituciones eclesiales dominantes.

Las reformas educativas han incrementado la privatización de escuelas y universidades y han facilitado la penetración de confesiones y congregaciones religiosas diversas, así como alternativas laicas en el campo educativo.

La mejora en las tasas de matriculación en los niveles educativos y las mencionadas reformas educativas tienden a impactar la cultura, modificando la mentalidad de las nuevas generaciones, haciéndolas más abiertas al cambio y a la diversidad, todo lo cual legitima las diferentes opciones en el campo espiritual y religioso.

\section{Las adhesiones religiosas se pluralizan}

Tomaremos como punto de partida los datos que nos provee el Censo Nacional de Población de Chile, porque en este país hemos realizado un conjunto de estudios durante estos últimos años.

Chile es un caso especial porque, de acuerdo a los datos disponibles de la década de los ochenta del siglo pasado, era el país con mayor proporción de evangélicos de Iberoamérica luego de Guatemala. Hoy, de acuerdo a los datos de Latinobarómetro 
(2007), es el país menos católico de Latinoamérica del Sur (luego de Uruguay), pero ya sólo se ubica en la media del protestantismo a nivel continental. Según esta misma fuente es el país que viene en tercer lugar en número de personas sin religión (10,2\%), sumados éstos a los ateos $(1,1 \%)$ a nivel continental. Es decir, Chile es un interesante caso en que el pluralismo religioso es mayor que en la mayoría de los países latinoamericanos, aunque no es el de mayor diversidad religiosa.

En los Censos Nacionales de Población chilenos de 1992 y 2002, los datos acerca de la afiliación religiosa según la edad indicaron una pluralización creciente de alternativas religiosas entre las generaciones más jóvenes. La Tabla 1 contrasta los dos polos de edad (las generaciones más jóvenes y aquellas de mayor edad) según la afiliación religiosa.

Tabla 1 - Afiliación religiosa por estratos polares de edad (Censos Chile - \%)

\begin{tabular}{|c|c|c|c|c|}
\hline & \multicolumn{2}{|c|}{$15-29$} & \multicolumn{2}{|c|}{ Más de 60} \\
\hline & 1992 & 2002 & 1992 & 2002 \\
\hline Católico & 74,01 & 66,18 & 80,83 & 76,94 \\
\hline Evangélico & 14,10 & 15,42 & 12,13 & 13,69 \\
\hline Sin religión/ateo & 7,42 & 11,09 & 3,34 & 4,50 \\
\hline Otra religión & 4,46 & 7,29 & 3,69 & 4,87 \\
\hline Total & 100 & 100 & 100 & 100 \\
\hline \multicolumn{5}{|c|}{ Diferencias } \\
\hline Católico & & $-7,83$ & & $-3,89$ \\
\hline Evangélico & & 1,32 & & 1,56 \\
\hline Sin religión/ateo & & 3,67 & & 1,16 \\
\hline Otra religión & & 2,83 & & 1,18 \\
\hline
\end{tabular}

Fuente: Censos Nacionales de Población, 1992 y 2002. Instituto Nacional de Estadísticas, Santiago de Chile. 
Es interesante anotar que la misma tendencia general se observa en el continente latinoamericano.

Tabla 2 - Latinoamérica: adhesión religiosa según tramos extremos de edad ${ }^{4}(\%)$

\begin{tabular}{c|c|c|c|c|c|c|c}
\hline Edad & $\begin{array}{c}\text { Cató- } \\
\text { lico }\end{array}$ & $\begin{array}{c}\text { Evan- } \\
\text { gélico }\end{array}$ & $\begin{array}{c}\text { Otra } \\
\text { reli- } \\
\text { gión }\end{array}$ & $\begin{array}{c}\text { Sin } \\
\text { reli- } \\
\text { gión }\end{array}$ & Ateo & $\begin{array}{c}\text { No res- } \\
\text { ponde }\end{array}$ & Total \\
\hline $\begin{array}{c}\text { 15 a } 29 \\
60 \text { y más }\end{array}$ & 66,2 & 16,4 & 3,1 & 9,5 & 1,2 & 3,6 & $\mathbf{1 0 0}$ \\
\hline $\begin{array}{c}\text { Dife- } \\
\text { rencias }\end{array}$ & $-11,0$ & 3,4 & 0,3 & 4,9 & 0,6 & & $\mathbf{1 0 0}$ \\
\hline
\end{tabular}

Fuente: Bases de datos Latinobarómetro 2006.

Los datos que nos ofrece Latinobarómetro para el año 2006 son concluyentes: para los estratos de mayor edad (más de 60 años), el porcentaje de no-católicos es de 22,7\%; en cambio, para los estratos jóvenes (de 15 a 29 años), es mayor, llegando al 33,8\%.

Todo ello significa que estamos ante un grupo de países en que el cambio religioso en adhesiones y creencias se observa, en gran medida, porque las generaciones más jóvenes ya no están adoptando necesariamente la religión de sus padres - a saber, para la mayoría, el catolicismo - y más bien están orientándose por dos tendencias: hacia las categorías "ninguna religión" o bien "creyente sin pertenencia a una iglesia" (diferencia de 4,9\%), o bien hacia los evangélicos (incluyendo opciones pentecostales y protestantismos históricos) (diferencia de 3,4\%). En una tendencia mucho más leve se orientan hacia el ateísmo o hacia otras alternativas religiosas entre las cuales es posible mencionar a los testigos de Jehová, adventistas, mormones, judíos y toda clase de cultos y nuevos movimientos religiosos. 
A primera vista los datos parecen hacer pensar en que estamos de retorno con las tesis clásicas de la secularización, es decir, que, dada la mayor modernización de las sociedades chilena y latinoamericanas, habría una tendencia al incremento mayor de alternativas alejadas de la religión e incluso de tipo antirreligiosas. Así parece indicar el hecho de que en los censos chilenos y en los datos de Latinobarómetro se incrementan con más velocidad los "sin religión y ateos".

Como procuraremos mostrar ahora, éste no parece ser el caso. El incremento del "ateísmo" ya no reúne las características que tuvo en el siglo XX cuando el cientificismo, de una parte, y la guerra fría, de otra, alimentaban movimientos que consideraban a las religiones como enemigas de la ciencia, del progreso y de la libertad y propiciaban el positivismo y el ateísmo, alentando filosofías materialistas, laicistas y anticlericales. Sabemos que el cambio de siglo ha traído nuevos aires a todo este debate y ya no estamos en los períodos en que se asociaba directamente el rechazo a la religión como una actitud de "política correcta" para los jóvenes que tenían puesta su mirada en las promesas futuras del progreso.

\section{Los creyentes "a su manera"}

Estamos en presencia de una diversidad de opciones en las adhesiones religiosas que nos muestran los censos y las encuestas, lo cual nos indica que no sólo las iglesias se han multiplicado en América Latina sino también los más diversos grupos, incluyendo grupos y cultos esotéricos y diversas formas de espiritualidades y misticismos postmodernos.

Con todo, hay un fenómeno al cual hemos venido prestando atención desde fines de la década de los 90. Se trata de la figura del creyente "a su manera". Esta categoría de adherente religioso no 
existe como categoría oficial de censos y encuestas y tampoco es una categoría que suele emplearse en las estadísticas de las iglesias, por razones que parecen evidentes. Analicemos con detalle cuál es el fenómeno al cual nos referimos.

En los últimos censos chilenos, en ambos años (1992 y 2002), no existía una alternativa para las personas que, por una parte, no quieran ser identificadas con una iglesia, pero, por otra parte, no quieran ser consideradas antirreligiosas o ateas. La única categoría que la encuesta del censo tenía para estas personas era: "indiferente o ateo". Las categorías de las encuestas generalmente hablan de "ninguna religión", o bien de "indiferentes" o bien de "agnósticos".

La evidencia encontrada en variados estudios en Chile y en México 5 nos indica que la categoría "sin religión" o "no religioso", en contexto latinoamericano, no puede confundirse o asociarse a la categoría "agnóstico o ateo". La denotación de la orientación religiosa de éstos últimos va en sentido contrario de las afirmaciones relativas a realidades trascendentes o sagradas.

Por el contrario, estudios cualitativos realizados por nosotros nos han mostrado que, en la generalidad de los casos, los denominados "sin religión" o bien "indiferentes" son, de hecho, personas que creen en realidades superiores - son "creyentes" - pero que generalmente no están dispuestas a verse involucradas con "la religión" que, por cierto, asocian a las iglesias establecidas. En este punto es dónde la sociología de las creencias se intersecta y - a veces - contradice a la sociología de la religión, entendida estrechamente ésta como sociología de las iglesias.

Ello significa que esas personas creen en Dios y en la mayoría de las creencias cristianas básicas (han nacido y han sido socializadas en una cultura cristiana), incluso pueden tener su propia "espiritualidad", y al mismo tiempo se distancian de las iglesias, de sus doctrinas, de su ética y de su clero, por considerarlos alienantes, 
represivos o anacrónicos. Por contraste, los “ateos" son generalmente un porcentaje muy pequeño de este grupo de personas jóvenes.

Estos datos evidencian una realidad que se aleja de lo previamente conocido y que en la década de los 60, en el siglo pasado, cuando el cambio cultural conllevaba la tendencia a la secularización, se interpretaba pronosticando un elevado porcentaje de ateos y de afiliaciones antirreligiosas, dado que así se observaba en las encuestas y en aquellos procesos políticos movilizadores de la izquierda, especialmente en su vertiente socialista de esos años (Smith, 1982).

Hoy, los estudios están entregando información acerca de la participación de las generaciones más jóvenes en una variedad de expresiones religiosas diferentes.

Al respecto, debemos considerar los datos de la Encuesta Nacional de Juventud realizada periódicamente por el Instituto Nacional de Juventud de Chile y que el año 2000 incluyó una categoría muy interesante y que dice relación con lo que venimos comentando (Tabla 4).

Como podemos observar, estos datos muestran la importancia de la categoría de los jóvenes que son "creyentes", pero no se identifican con alguna iglesia. Son un $26,3 \%$ de la muestra total (N =3710).

En relación a este tipo de creyentes, en los últimos ocho años hemos realizado estudios sobre afiliación religiosa dónde hemos explorado nuevas categorías (Tabla 4). 


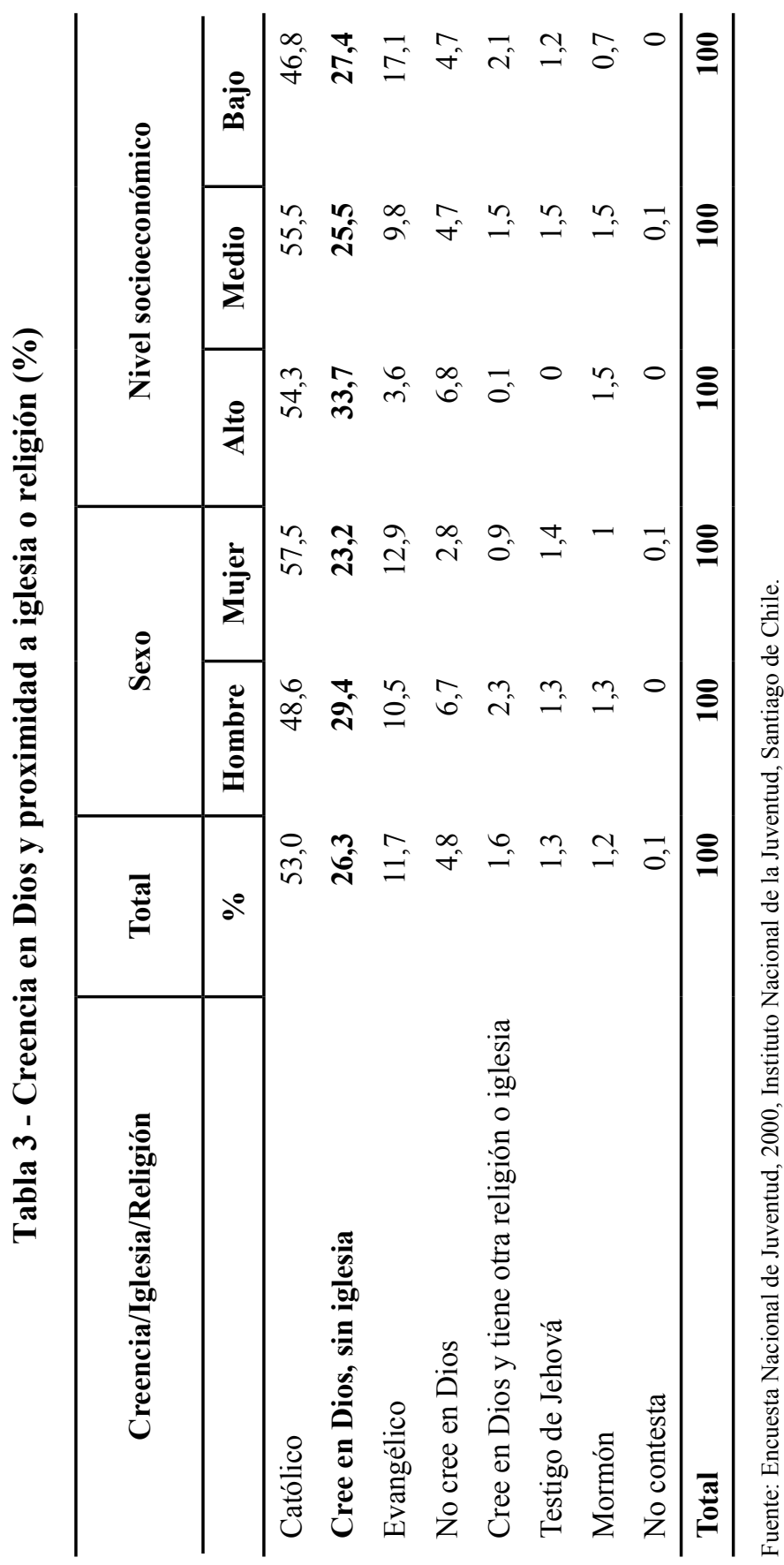




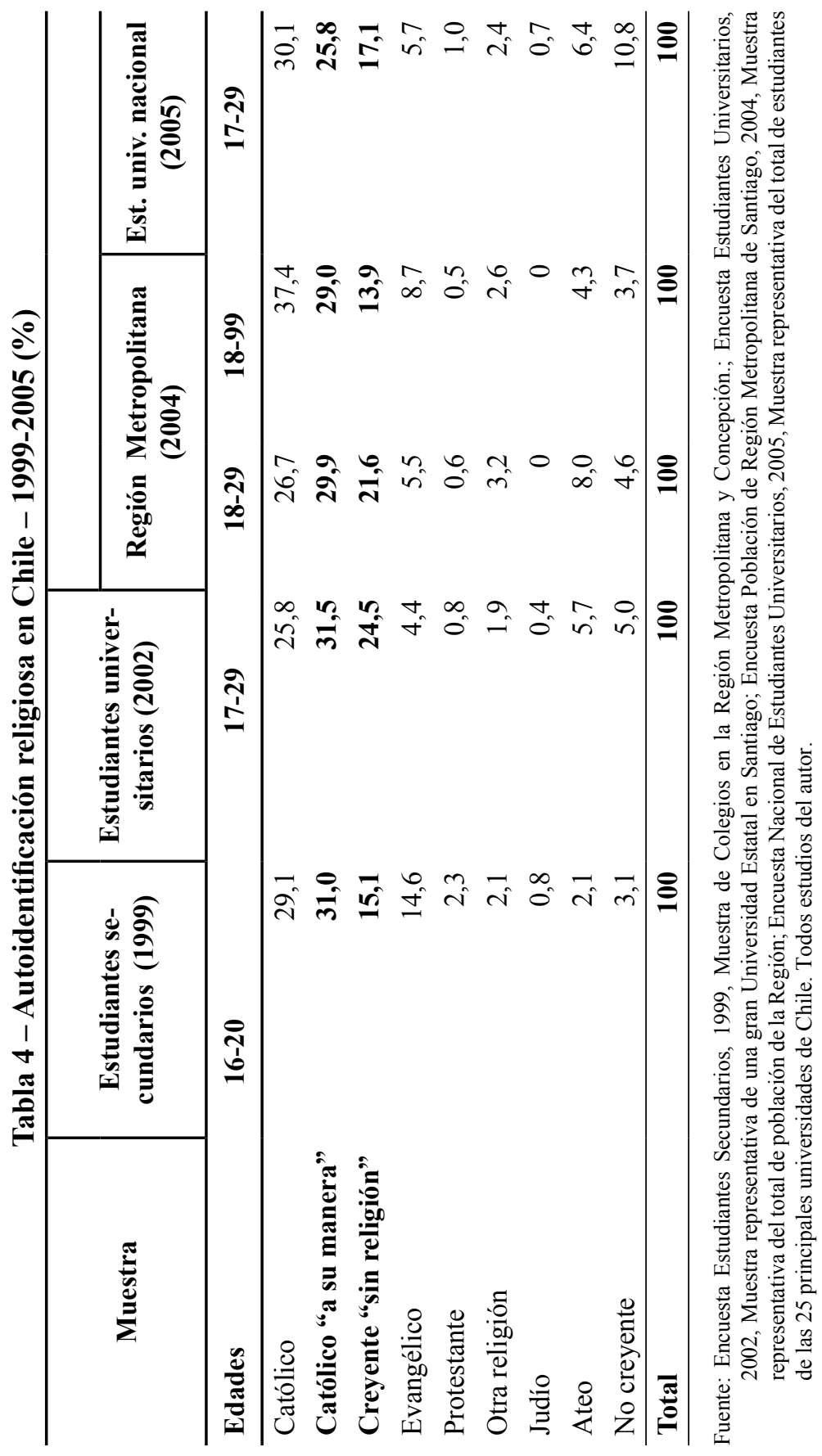


Como observamos, entre $25 \%$ y $30 \%$ de los estudiantes secundarios y universitarios declara ser "católico" sin reparos. Entre $26 \%$ y $31 \%$ de los estudiantes secundarios y universitarios se autoidentifica como católicos "a su manera", sugiriendo que toman distancia del Catolicismo oficial y eclesiástico. Es importante mencionar que entre $15 \%$ y $25 \%$ de los estudiantes secundarios y universitarios se identifica como "creyentes sin religión", mientras que sólo $5 \%$ de los estudiantes secundarios y $11 \%$ a $17 \%$ de los estudiantes universitarios se identifican como "no creyentes o ateos".

Para hacer una interpretación válida es necesario aclarar que las muestras de estudiantes secundarios y universitarios no son representativas del país entero; y sólo la encuesta de la Región Metropolitana de 2004 es representativa de la población regional total y nos permite hacer un análisis comparativo.

Con todo, hay algunas tendencias generales a ser mencionadas. Las diferencias entre estudiantes secundarios y universitarios son pertinentes. La diferencia más sustancial se da en las categorías "ateo" y "no creyente", que es superior en ambos casos para los estudiantes universitarios.

En la IV Encuesta Nacional de Juventud (2003, N = 7189), que tenía otra clasificación para la afiliación religiosa, el $23 \%$ de los encuestados afirmaron que "yo no me siento cerca de ninguna religión", pero sólo 4,5\% declararon ser "no creyente en Dios o cualquier divinidad".

En la V Encuesta Nacional de Juventud (2006; $\mathrm{N}=6345$ ), es significativo que el $24,5 \%$ plantea no sentirse identificado con "ninguna religión", siendo los hombres con un 29,8\% los que sobresalen en esta situación, mientras que las mujeres lo reportan en un 19,1\%. Analizados los datos con mayor detención, se observa que no todos los que declaran no adherir a ninguna opción religiosa 
son "no creyentes". Al menos un tercio (66\%) de ese $24,5 \%$ general, que declaran "ninguna religión", se confiesa creyente en Dios. En el total de los encuestados, esto significa que solamente hay cerca de un $8 \%$ de "no creyentes" consistentes.

Si observamos la categoría "católico" de la Tabla 4, veremos que es superior $(37,4 \%)$ para la muestra total de la población metropolitana que cualquier valor en la otra muestra de juventud o grupos de estudiantes. Los “creyentes sin religión”, en cambio (qué es $14 \%$ para la población metropolitana entera), tienden a ser superiores en las muestras de juventud (15\% en estudiantes secundarios, $17 \%$ para muestra nacional de estudiantes universitarios).

La evidencia que nos viene de la Muestra de la Región Metropolitana (Tabla 5) sugiere que la tendencia en "los creyentes sin religión" es estar principalmente presente en las generaciones más jóvenes; ella se corrobora pero inversamente para los católicos: ellos están principalmente presentes en las generaciones mayores. Hay también una tendencia ligera para aquellos que se declaran católicos "a su manera" de estar más presente entre los adultos jóvenes y adultos de la edad madura, entre 30 y 49 años. Todos estos datos son estadísticamente significativos [Chi2(10) =97,63; $\mathrm{p}=0,000]$. 


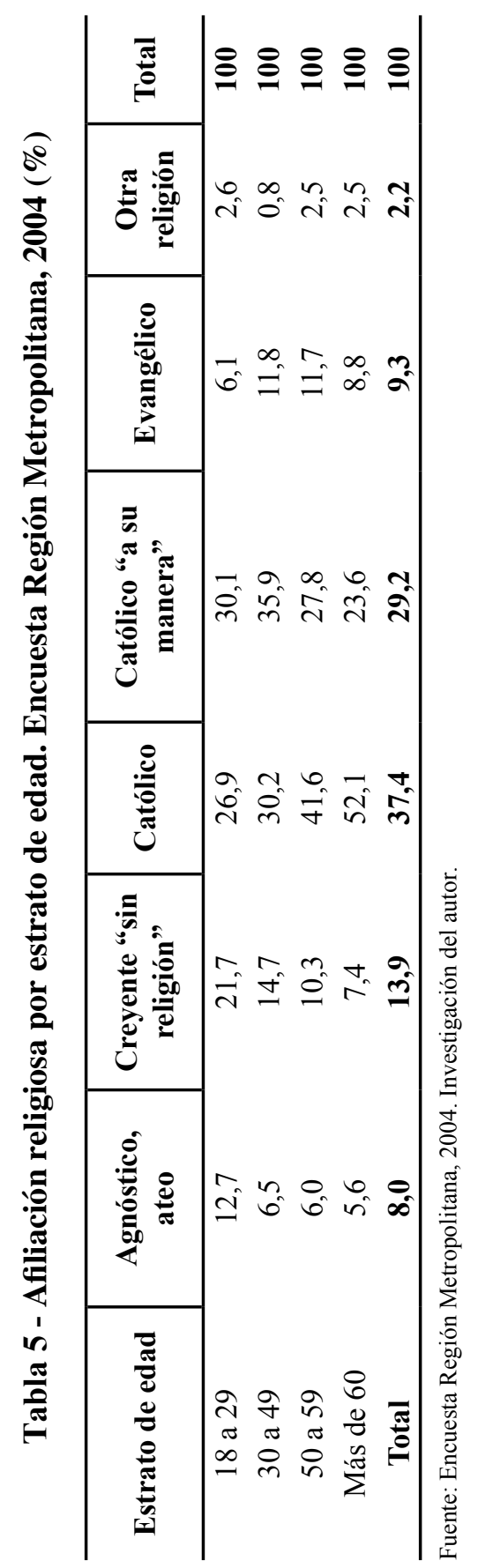


La tendencia general a ensanchar el espectro de opciones religiosas (y el declive en el número de católicos) es mayor entre los estudiantes y las generaciones más jóvenes. Parece ser que para los estudiantes universitarios se manifiesta una tendencia a que predominen allí opciones de tipo "no creencia" o ateísmo.

Nuestra hipótesis principal aquí es que la racionalidad para esta tendencia es que las personas que tienen un nivel superior de educación formal tenderán a optar por opciones más racionalizadas y no formales ni institucionales de creencias (creencia "a su manera") o por abandonar todas las referencias a la religión en su vida (agnosticismo o ateísmo).

Indagando con mayor profundidad en la categoría "creyente sin religión" o "a su manera", es claro que estamos ante personas que tienen mayores niveles de desconfianza institucional, apuntando su identificación religiosa en un sentido extraeclesial.

De hecho, en el estudio de la Región Metropolitana de 2004, los que se identifican como "católicos" a secas declaran mayor confianza hacia la Iglesia y su jerarquía religiosa (los sacerdotes católicos). Los "católicos" declaran un 46\% de "mucha confianza" en los sacerdotes; en tanto, los "católicos a su manera", sólo en un $26 \%$. Entre los declarados creyentes "sin religión", 53\% desconfían de los sacerdotes católicos. (Estos datos tienen significación estadística: Chi2 $(10)=193,371, \mathrm{p}=0,000$; Pears $=0,06697, \mathrm{p}=$ 0,029; Spear $=0,0496, \mathrm{p}=0,030)$.

Ésta es una señal clara que "sin religión" debe interpretarse como una posición que quiere enfatizar una disidencia respecto de la Iglesia católica oficial, iglesia monopólica y mayoritaria. Pero no es antirreligioso: es otro tipo sociológico de creyente, es decir, reconoce su fe en Dios y en valores cristianos. La evidencia del estudio sobre universitarios a nivel nacional de 2005 va en la misma dirección. 
Retomando los datos de la Tabla 4, si se agregan los datos referidos a los católicos "a su manera" a aquellos de los "creyentes sin religión", tenemos a $46 \%$ de la muestra de estudiantes de la escuela secundaria, y a $43 \%$ a $56 \%$ de estudiantes universitarios, datos de muy alta relevancia sociodemográfica. Desde el punto de vista teórico eses datos podrían interpretarse como los formas de "disidencia" religiosa en un campo cultural-nacional donde el Catolicismo es hegemónico en la cultura. Los datos del estudio de la Región Metropolitana de 2004 van en la misma dirección: 51\% de las personas entre los 15 a 29 años pueden ser clasificados en la categoría de "disidentes" del Catolicismo oficial, y $43 \%$ de la población general (que incluye todas las edades).

Como se ha observado en América del Norte, la práctica religiosa tradicional en las iglesias está cayendo. Pero este hecho no hace pensar en una falta de interés religioso en absoluto sino en un cambio en los intereses hacia nuevas direcciones. En Europa, las investigaciones dirigidas por Lambert, en Francia, han llamado a este tipo de creyentes los "cristianos culturales", o bien se han referido a la figura del "deísta cristiano" (Lambert, 2003).

En general, los datos consignados son coincidentes con estudios realizados en sectores juveniles a nivel internacional y evidencian una "desinstitucionalización" de las creencias. Esto es, hay una progresiva toma de distancia de parte de muchos creyentes respecto a las instituciones eclesiales. Muchos jóvenes no necesariamente abandonan sus creencias, más bien no quieren estar ligados a una determinada confesión, sus dogmas, instituciones y normas (Injuv, 2007).

\section{La educación como un factor que influye en las opciones religiosas}

Se ha afirmado en la teoría clásica que la modernización genera, entre sus procesos, la elevación de la tasa de escolarización, lo que 
va transformando la cultura tradicional. En efecto, se ha considerado a la educación moderna como un factor de secularización que reduce la religiosidad y promueve las opciones racionales y la crítica de tradición. En los datos que tenemos del caso chileno se observa que el factor educativo es pertinente para el análisis de los cambios en la mentalidad religiosa, pero esta influencia no va necesariamente en el sentido de lo que postulaba linealmente el paradigma de la modernización. Lo que observamos es que si bien se incrementan las opciones racionalistas y secularizadoras con la escolarización, por otra parte se incrementan también otras opciones y búsquedas espirituales.

Uno de los indicadores principales del proceso de modernización en Chile es la proporción creciente de alfabetización. En la última década (según los censos de 1992 y de 2002), Chile pasó de $94,6 \%$ a $95,8 \%$ en la proporción de alfabetismo. Por otro lado, un aumento muy significativo ha tenido lugar a nivel de educación formal. El censo de 2002 sugiere que el nivel de niños que asisten a la educación preescolar casi fue doblado. Con respecto a educación secundaria y superior, el número de las personas que egresaron de esos niveles aumentó de 1.072.198 en 1992 a 2.284.036 en 2002 . Esto es un aumento de $9 \%$ en el caso secundarios y de $16,4 \%$ en el caso universitarios en relación a la matrícula total en cada nivel.

Cuando se comparan estos datos con aquellos sobre identificación religiosa en los estratos de edad de 15 a 29 años, se encuentra que, para niveles superiores de educación formal, se da una mayor cantidad de personas que se declaran sin religión o ateos o agnósticos. En la educación básica, éstos alcanzan 9,4\% del total; en las personas que han alcanzado educación secundaria, el porcentaje aumenta a $9,91 \% \mathrm{y}$, con aquéllos que han alcanzado la educación superior, llega a 15,31\%. En los estratos de personas que recibieron 6 años o más de educación superior, el porcentaje de ateos y agnósticos y aquéllos que se declaran sin afiliación religiosa alcanza su punto mayor en $20,35 \%$. 
Analicemos los datos que trae el censo chileno para la Región Metropolitana en la cual está la ciudad de Santiago de Chile, una ciudad bastante moderna, con más de seis millones de habitantes.

Tabla 6 - Religión por nivel educativo. Chile: Censo Nacional de 2002, Región Metropolitana (población mayor de 15 años)

\begin{tabular}{l|c|c|c|c|c}
\hline $\begin{array}{c}\text { Nivel educa- } \\
\text { tivo }\end{array}$ & Católico & $\begin{array}{c}\text { Evan- } \\
\text { gélico }\end{array}$ & $\begin{array}{c}\text { Otra } \\
\text { religión }\end{array}$ & $\begin{array}{c}\text { Ninguna } \\
\text { o ateo }\end{array}$ & Total \\
\hline $\begin{array}{l}\text { Básica } \\
(8 \text { o menos })\end{array}$ & 814308 & 234442 & 86905 & 83853 & $\mathbf{1 2 1 9 5 0 8}$ \\
$\begin{array}{l}\text { Secundaria } \\
(9 \text { a 12) }\end{array}$ & 1468781 & 277466 & 161951 & 202798 & $\mathbf{2 1 1 0 9 9 6}$ \\
$\begin{array}{l}\text { Técnica y Uni- } \\
\text { versitaria }\end{array}$ & 846160 & 83265 & 106672 & 185366 & $\mathbf{1 2 2 1 4 6 3}$ \\
\hline Total & $\mathbf{3 1 2 9 2 4 9}$ & $\mathbf{5 9 5 1 7 3}$ & $\mathbf{3 5 5 5 2 8}$ & $\mathbf{4 7 2 0 1 7}$ & $\mathbf{4 5 5 1 9 6 7}$ \\
\hline Porcentajes & & & & & \\
\hline $\begin{array}{l}\text { Básica } \\
(8 \text { o menos })\end{array}$ & 66,77 & 19,22 & 7,13 & 6,88 & $\mathbf{1 0 0}$ \\
$\begin{array}{l}\text { Secundaria } \\
\text { (9 a } 12)\end{array}$ & 69,58 & 13,14 & 7,67 & 9,61 & $\mathbf{1 0 0}$ \\
$\begin{array}{l}\text { Técnica y Uni- } \\
\text { versitaria }\end{array}$ & 69,27 & 6,82 & 8,73 & 15,18 & $\mathbf{1 0 0}$ \\
\hline Total & $\mathbf{6 8 , 7 4}$ & $\mathbf{1 3 , 0 8}$ & $\mathbf{7 , 8 1}$ & $\mathbf{1 0 , 3 7}$ & $\mathbf{1 0 0}$ \\
\hline & $-1,97$ & 6,15 & $-0,68$ & $-3,49$ & \\
\hline & 0,83 & 0,07 & $-0,14$ & $-0,76$ & \\
\hline & 0,53 & $-6,26$ & 0,92 & 4,81 & \\
\hline Diferencias & & & & \\
\hline
\end{tabular}

Fuente: Censo Nacional de Población, 2002. Instituto Nacional de Estadísticas, Santiago de Chile. Tabulación del autor. 
Se observa lo que hemos ya analizado acerca de los "sin religión" y los "agnósticos" y "ateos." En cuanto a las otras opciones religiosas, se aprecia que los evangélicos están influidos negativamente por los niveles crecientes de educación: a mayor nivel educativo se reduce la proporción de evangélicos.

Dado que las generaciones más jóvenes son aquellas que cada vez más reciben el impacto del sistema educativo moderno, observemos los datos correspondientes a las personas entre 15 y 29 años para todo el país:

Tabla 7 - Escolarización y religión en Chile. Estrato etario: 15 a 29 años. Censo Nacional de 2002 (\%)

\begin{tabular}{|c|c|c|c|c|c|}
\hline \multicolumn{6}{|c|}{ Población de 15 a 29 años por educación y religión } \\
\hline Nivel educativo & Católico & $\begin{array}{l}\text { Evan- } \\
\text { gélico }\end{array}$ & $\begin{array}{c}\text { Otra } \\
\text { religión }\end{array}$ & $\begin{array}{c}\text { Ninguna } \\
\text { o ateo }\end{array}$ & Total \\
\hline $\begin{array}{l}8^{\circ} \text { Grado o } \\
\text { menos }\end{array}$ & 61,84 & 22,20 & 6,48 & 9,49 & 100 \\
\hline $\begin{array}{l}\text { Enseñanza Se- } \\
\text { cundaria }\end{array}$ & 67,17 & 15,90 & 7,03 & 9,91 & 100 \\
\hline $\begin{array}{l}\text { Enseñanza Supe- } \\
\text { rior o universi- } \\
\text { taria }\end{array}$ & 67,34 & 8,72 & 8,62 & 15,31 & 100 \\
\hline Total & 66,18 & 15,43 & 7,30 & 11,09 & 100 \\
\hline \multirow{3}{*}{ Diferencias } & $-4,34$ & 6,77 & $-0,82$ & $-1,60$ & \\
\hline & 0,98 & 0,47 & $-0,27$ & $-1,19$ & \\
\hline & 1,16 & $-6,70$ & 1,32 & 4,22 & \\
\hline
\end{tabular}

Fuente: Censo Nacional de Población, 2002. Instituto Nacional de Estadísticas, Santiago de Chile. Tabulación del autor. 
De hecho, entre 15 y 29 años, los católicos con menor educación formal son proporcionalmente menos. Los evangélicos con menor educación formal son proporcionalmente más, $\mathrm{y}$, en un nivel educativo superior, son proporcionalmente menos. La menor proporción del número de evangélicos con mayor educación formal es ocupada por "no creyentes" o "sin religión" y, en una ostensible menor proporción, por católicos y “otras religiones".

El estudio de la Región Metropolitana de 2004 nos permite reforzar las observaciones empíricas y verificar estas tendencias.

Para evitar el sesgo de la edad en la relación causal entre la educación y religión, hemos aplicado una prueba nominal de Correlación de Cramer a cada estrato de edad, con los siguientes resultados:

- 18 a 29 años $(\mathrm{CrV}=0,162, \mathrm{p}=0,052)$;

- 30 a 49 años $(\mathrm{CrV}=0,197, \mathrm{p}=0,000)$;

- 50 a 59 años $(\mathrm{CrV}=0,173, \mathrm{p}=0,410)$;

- 60 años o más $(\mathrm{CrV}=0,181, \mathrm{p}=0,687)$.

Esto significa que las variables edad y educación están influyendo en la religión. Con un test de correlación nominal se verifica que la educación está significativamente correlacionada con la religión en los primeros estratos de edad (18 a 29) y tiene una correlación significativa mayor en los segundos estratos de edad (30 a 49). En los otros estratos de edad (entre 50 y 59 y más de 60), ellos no evidencian correlación.

En otros términos, este estudio está mostrando que la educación moderna y formal es un factor determinante que influye en las opciones religiosas entre las generaciones jóvenes y medias, aunque no en las generaciones más viejas. 


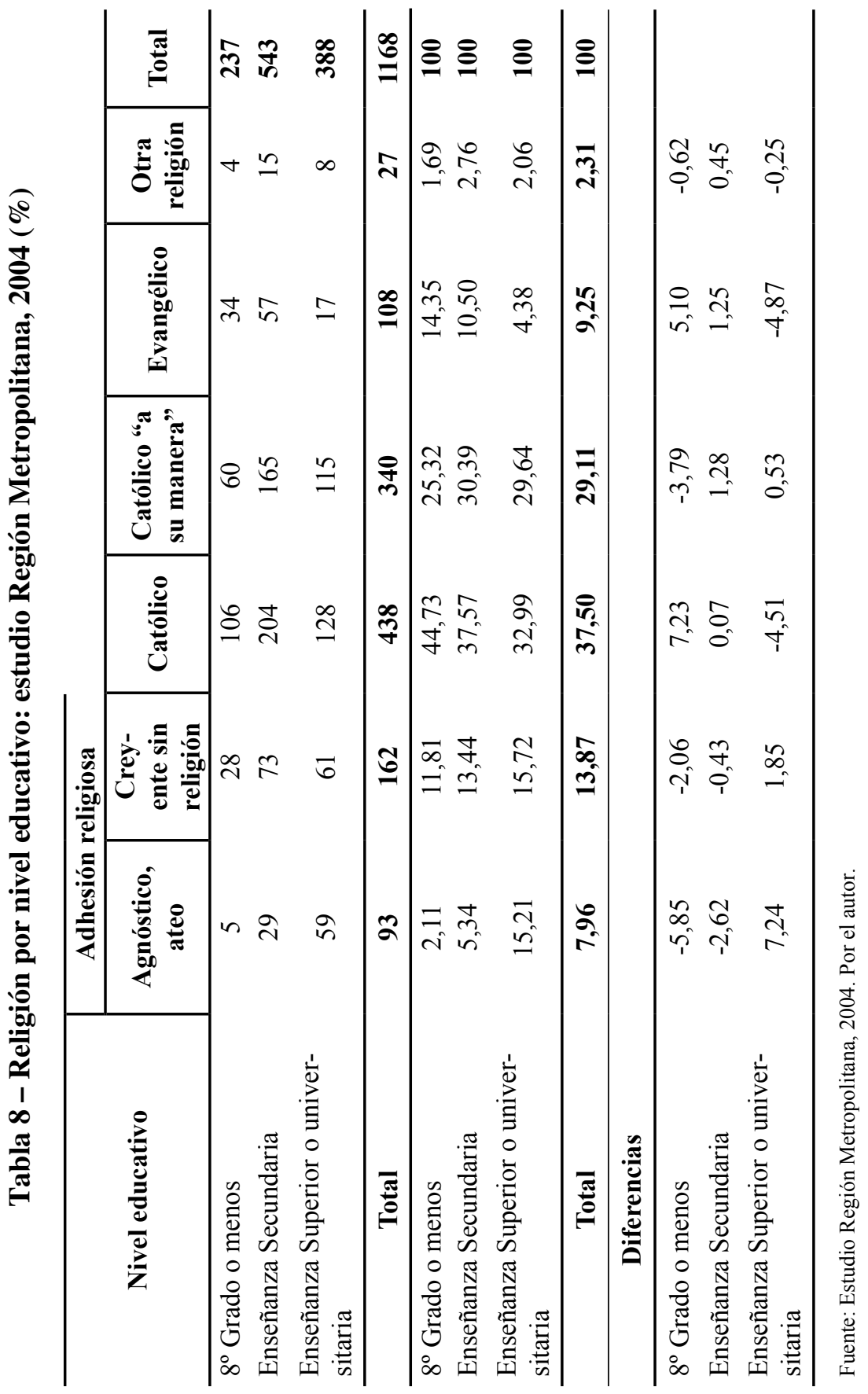


Al respecto, hemos analizado los datos que nos entrega Latinobarómetro (2007) en sus encuestas para toda América Latina. Las tendencias generales observadas nos sugieren que el caso chileno no es una excepción. Los datos mencionados nos entregan resultados similares: los evangélicos son proporcionalmente más entre los menos educados en las encuestas de los siguientes países: Argentina, Chile, Paraguay, Perú, Uruguay y Venezuela.

Los casos contrarios, en los cuales la tendencia es a encontrar un mayor número de evangélicos a medida que subimos en el nivel educativo, son menos: República Dominicana y El Salvador. Los casos mesoamericanos de México, Guatemala, Honduras y Panamá no presentan tendencia definida y los casos de Brasil y Colombia presentan tendencias diversificadas y más plurales.

Estos datos nos muestran una tendencia al cambio religioso y cultural que estarían asociados a los grandes cambios en los sistemas educativos durante la última mitad del siglo XX. Las generaciones de mayor edad (50 años o más) asistieron a la escuela hace cuarenta o más años (aquéllos que tenían la oportunidad de ir a la escuela), cuando las opciones culturales y religiosas y las condiciones pedagógicas eran más tradicionales y la instrucción no recibía el impacto de los medios de comunicación de masa y las nuevas tecnologías de hoy.

La influencia cultural de la globalización en la educación y en la socialización de los años ochenta en adelante es más evidente para las generaciones jóvenes (es decir, para aquellas personas que tienen entre 15 y 35 años).

El conjunto de datos e informaciones que hemos recopilado y analizado nos posibilita desarrollar una serie de postulados que, a manera de hipótesis, se pueden formular como sigue:

1. Los niveles crecientes de escolarización están generando cambios religiosos incrementando las alternativas al 
catolicismo tradicional y acrecentando el pluralismo en las adhesiones y creencias religiosas (católicos "a su manera", creyentes sin religión, agnósticos/ateos y otras religiones).

2. En una tendencia paralela a la anterior, se observa que el incremento de las tasas de escolarización se da asociado con el decremento del porcentaje de evangélicos.

3. La confirmación de las tendencias establecidas indicaría que, al incrementarse las tasas de escolarización en el futuro de Chile y América Latina (proceso que ya está en marcha por las reformas y modernización educativa ${ }^{6}$ ), el pluralismo religioso se vería incrementado y el crecimiento de los católicos y de los evangélicos disminuiría consecuentemente.

Un reciente estudio de 2007 sobre una muestra representativa de Evangélicos en dos de las regiones de $\mathrm{Chile}^{7}$ con mayor proporción de esta opción religiosa, nos sugiere que efectivamente se estaría dando un proceso de mayor escolarización entre los jóvenes evangélicos.

A menor edad, mayor nivel educativo entre los evangélicos; a mayor edad, inversamente menor nivel educativo. Con todo, la pregunta que corresponde hacerse es: ¿disminuirá ello el crecimiento de los evangélicos en la medida en que avancen las modernizaciones y los niveles educativos se incrementen? que es, como hemos adelantado, una de nuestras hipótesis.

La hipótesis contraria podría ir en un sentido distinto afirmando que los mejores niveles educativos cambiarían la naturaleza de la inserción social de los evangélicos sin afectar mayormente su crecimiento. Es decir ¿cambiará la forma de inserción de esas iglesias en la sociedad y se tornarán instancias más presentes e integradas al quehacer nacional dejando atrás su carácter de "minoría religiosa" 


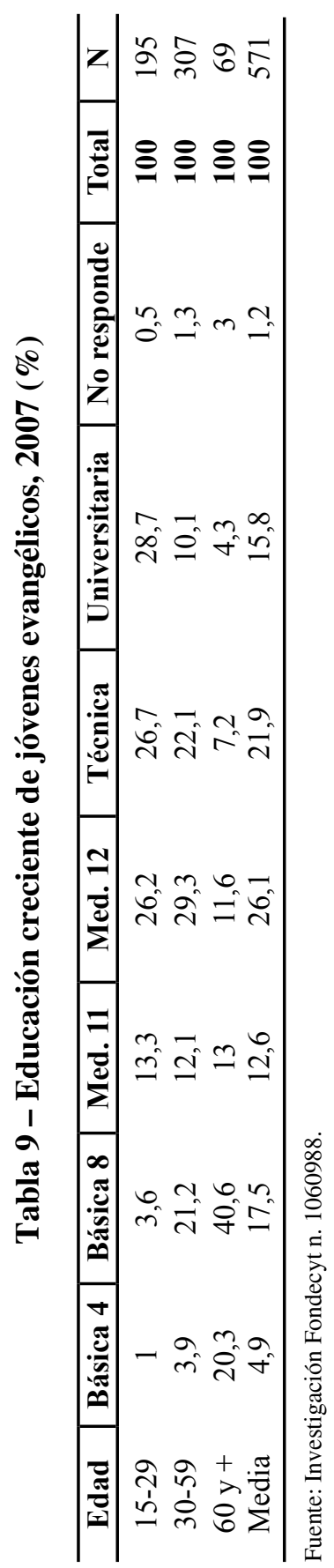


marginada? Analizaremos esto cuando toquemos el acápite sobre religión y ciudadanía.

Por otra parte, si nos enfocamos en los jóvenes y estudiantes (entre 15 y 29 años) en el contexto histórico de una élite que está viviendo los cambios de un país en desarrollo, la pregunta es: ¿el pluralismo religioso creciente es solamente efecto de un grado superior de educación o influye también la oferta educativa institucional (el hecho de que haya o no escuelas confesionales)?

El análisis de los datos de nuestros estudios (Tabla 4) acerca de la influencia del tipo de escuela en la pluralización de alternativas religiosas no es concluyente.

Las escuelas secundarias confesionales no necesariamente registran porcentajes más elevados de jóvenes que se declaran "católicos". Sólo en la escuela privada pagada de estratos socioeconómicos altos encontramos una proporción superior de católicos $(72 \%)$. Esto es probablemente debido al hecho que el catolicismo es un rasgo cultural de las clases superiores en Chile. En muchas escuelas secundarias laicas o estatales encontramos una mayor proporción de católicos "a su manera", pero la tendencia no es permanente.

A nivel de universidades, aquellas confesionales católicas efectivamente registran mayor proporción de "católicos" y menor de creyentes "a su manera" y de no creyentes. Las universidades públicas y laicas, por su parte, registran mayor proporción de creyentes "a su manera", de "otras confesiones" no católicas (protestantes, mormones, judíos, etc.) y de no creyentes y ateos. Las diferencias respectivas oscilan entre el 3 y el 12\%. Es decir, no son pronunciadas.

Lo que es importante subrayar aquí es que parece que el factor institucional, si bien influye, no juega un papel decisivo en la pluralización de alternativas. 
Efectivamente, las reformas educativas han ampliado la oferta y en los años recientes han aparecido nuevas instituciones laicas y se han diversificado las escuelas y universidades privadas - lo que amenaza con el privilegio que tenía la educación católica en los países latinoamericanos. Todo ello, si bien en algunos casos influye considerablemente, en otros no influye para nada, por lo que no parece ser el factor decisivo en la pluralización de creencias y adhesiones religiosas de las generaciones jóvenes.

Mucho más relevante parece ser la influencia de valores culturales - vehiculizados por el sistema y la cultura escolar - que están generando creyentes "a su manera" e incluso en las escuelas católicas. En el caso de las universidades, prácticamente no hay diferencia en la proporción de católicos "a su manera" existente en las universidades católicas y en las universidades laicas y públicas.

Nuestra hipótesis interpretativa en este respecto es que la exposición general a una cultura más liberal y crítica, en las élites más educadas (estudiantes universitarios analizados) da la oportunidad de cuestionar la identificación religiosa tradicional. Una cultura ilustrada en este caso lleva, de una parte, a la secularización clásica: se incrementa el no creyente, pero también se bifurca en otra dirección: lleva a nuevas alternativas y búsquedas espirituales de tipo no ortodoxo. La mayoría de los creyentes "a su manera" son de hecho creyentes en la astrología, el tarot, la reencarnación, la New Age y en toda clase de misticismos y neoesoterismos contemporáneos.

\section{Pluralismo religioso: ¿construcción de ciudadanía democrática?}

Podría pensarse que incrementar el pluralismo religioso quebrando el monopolio que el catolicismo mantuvo por centurias sería saludable para la democracia latinoamericana, ya que posibilita introducir la diversidad religiosa y cultural en las bases mismas de la 
sociedad civil. Siendo válida esta afirmación, ella es muy incompleta porque los fenómenos religiosos y sus impactos en el campo cívico y político no obedecen a causalidades unidimensionales ni mucho menos de tipo lineal.

La pregunta por la influencia de la religión en el campo cívico-político latinoamericano tiene muchas aristas y ciertamente nos conduce a la vieja relación Iglesia-Estado, por una parte, y a la relación entre las expresiones y movimientos religiosos y sus influencias en la construcción de los movimientos sociales y políticos, por otra.

En los años recientes, los cambios políticos experimentados en América Latina, con el advenimiento al poder de tantos regímenes de centroizquierda o populistas, como en Brasil, Venezuela, Argentina, Ecuador, Bolivia, Chile, Nicaragua, y recientemente con la elección del ex obispo Lage de Paraguay, nos llevan a considerar la dimensión religiosa que ha estado involucrada en dichos procesos.

De hecho, lo cierto es que ya no estamos en presencia de un factor religioso que era rápidamente identificado como contrapeso político hacia la derecha durante casi toda la vigencia del siglo XIX y la primera mitad del siglo XX en la historia latinoamericana. En efecto, durante décadas, en las sociedades oligárquicas, el catolicismo tuvo su expresión política en los conservadurismos de diverso cuño. En su lucha contra el liberalismo y el laicismo, los partidos conservadores llegaron incluso a declararse defensores de la Iglesia. Luego surgieron, en la sociedad de masas, las alternativas de nueva cristiandad y los proyectos - en pocos casos exitosos - de partidos demócratas cristianos. Finalmente vino toda la renovación Conciliar y las reformas de la Conferencia de Obispos de Medellín en adelante: la Iglesia católica se transformó en un factor de cambios y de generación de liderazgos para promover la transformación social. La historia que sigue, con la expansión de las comunidades de base y la teología de la liberación, es ya conocida. 
Todo ello posibilita comprender que ahora, detrás de la conformación de muchos movimientos sociales, movimientos indígenas y regímenes movilizadores, en esta última década en el continente - desde México hasta la Patagonia -, detrás de cambios políticos sustanciales, ya no solo hacia la derecha, sino hacia el centro y también hacia la izquierda, hay un trabajo de las iglesias que tuvo su origen en la promoción social y que culminó en el insumo hacia dichos movimientos sociales.

Es un hecho que la religión ha estado siempre vinculada con el poder y así lo ha analizado la sociología y la ciencia política. En efecto, todo fenómeno religioso conlleva poder sagrado, pero y precisamente por ello, es un factor de poder en el juego de poderes. La religión puede ser considerada como una forma de lo que Nye (1990) llama soft power y uno de los más eficaces por su legitimidad simbólica. Más todavía en el mundo contemporáneo donde los factores culturales son cada vez más relevantes, el poder simbólicoreligioso es un factor de poder enorme. De hecho, el poder simbólico, legitimado extra-socialmente, es un signo poderoso empleado para reforzar a la fuerza material, ya sea para imponer un imperio y/o para resistirlo.

Pero no es esta la óptica desde la cual queremos abordar el problema de la religión y la ciudadanía en este artículo, sino más bien desde el análisis de la contribución de las adhesiones religiosas, de esta nueva mentalidad religiosa naciente, menos institucional, hacia la construcción de una ciudadanía democrática, despolitizada, mucho más inspirada en valores que en ideologías y mucho menos preocupada del apoyo a los partidos políticos que en el trabajo de construcción de las redes en la sociedad civil.

Es un hecho reciente que la recuperación de la democracia en muchos procesos a nivel mundial, desde la caída del muro de Berlín, 
en Europa, Europa del Este, Asia y América Latina e incluso en algunas partes de África, ha traído a la actualidad no sólo el discurso y la práctica de los derechos humanos, sino que también el discurso acerca de la ciudadanía.

Fue la democracia liberal, en su larga trayectoria, la que sentó las bases de la conquista de las libertades fundamentales y con ellas del derecho de ciudadanía entendido democráticamente. Pero digamos de partida que la concepción liberal de ciudadanía tiene sus limitaciones por cuanto apela a una ciudadanía pasiva en el ejercicio de los derechos individuales cívico-políticos del ciudadano. En efecto, las demandas democráticas de las sociedades contemporáneas apelan a una "ciudadanía activa" (González, 2001) que incluye una acción ciudadana en todos los ámbitos de los derechos, incluyendo los derechos sociales, económicos y culturales.

A un nivel general, la mayoría de los autores concuerda con Marshall (1998), quién identifica ciudadanía abarcando un sentido civil de derechos básicos y protecciones, derechos políticos del ciudadano (derecho a voto y de reunión) y acceso a la ciudadanía social (el empleo, alojamiento, salud y otros beneficios y bienestar sociales).

El concepto de ciudadanía se ha ido ampliando con el tiempo. Desde la ciudadanía civil y política se ha puesto énfasis en la ciudadanía social (Marshall y Bottomore, 1998), la ciudadanía étnica (Kymlicka, 1996) de migrantes e incluso en la denominada ciudadanía universal (Tabin, 2000). Si bien no puede haber una linealidad entre ellas y más bien habría que verlo como una tensión permanente sobre sus contenidos, el análisis de la ciudadanía es un enfoque útil para el análisis social. Hay quienes han preferido hablar de derechos humanos como una superación de la tematización de la ciudadanía, pero ello le resta el énfasis en la participación del actor social (Turner, 2006). 
La discusión actual acerca de la ciudadanía plantea la relación con el carácter universal de ésta en su concepción clásica y el hecho de que estamos ante una sociedad cada vez más diversa y plural (Kymlicka y Norman, 1994). Algunos teóricos plantean que debe sobrepasarse el debate de la diversidad para centrarse en el universalismo de la ciudadanía, otros autores insisten en que no es posible hablar hoy de ciudadanía sin asumir que la diversidad y el pluralismo deben y pueden ser integrados al marco mismo de la definición de ciudadanía democrática en el siglo XXI (Shafir, 1998).

Ahorabien, lageneración de un nuevo panorama sociorreligioso plural en América Latina ha transformado los términos en los cuales se daba la relación religión y política, y por ende los términos en los cuales se daba la vieja relación entre el catolicismo predominante y la ciudadanía en sociedades latinoamericanas que, hasta mediados del siglo XX, todavía no alcanzaban niveles de democratización política universal. Como dice Levine (2005), el contexto generado por el pluralismo amplía el campo de influencias e interacción mutua entre religión y política y deja a las instituciones de iglesia fuera del centro del escenario.

La generación de un vocabulario práctico de derechos, que incluye la defensa de los derechos humanos, pero también genera sujetos autónomos, ha ido ciertamente generando un nuevo contexto de encuentro entre las corrientes y prácticas seculares y religiosas y funda una nueva relación - teórica y empírica - entre religión y ciudadanía.

\section{¿Cómo se da esta relación hoy en día en los fieles latinoameri- canos?}

De partida, como veremos, nuestro foco de atención no serán las iglesias ni la relación Iglesia-Estado, ni las acciones políticas de 
movimientos inspirados religiosamente, sino lo que acontece con los fieles y sus prácticas inspiradas por su mentalidad, sus valores y sus opciones. Profundizaremos en el pluralismo de creencias $\mathrm{y}$ adhesiones religiosas y de su relación con opciones cívicas y no necesariamente con opciones político-ideológicas que, como sabemos, están hoy desprestigiadas.

Las preguntas que nos hacemos son: ¿los creyentes "a su manera" son más inorgánicos en lo cívico y político dado que tienden a ser inorgánicos en el campo religioso? ¿Los católicos y los evangélicos son verdaderamente pluralistas en el campo cívicodemocrático? ¿Ciertas adhesiones religiosas inhiben la participación en las organizaciones de la sociedad civil? ¿Es posible encontrar tendencias no democráticas en ciertas opciones religiosas actuales?

Revisemos esta temática en tres dimensiones que nos han parecido claves a la luz del pluralismo de adhesiones religiosas que hemos observado: inicialmente, analizaremos lo que sucede con los creyentes "a su manera" y la ciudadanía democrática, luego con los evangélicos. Finalmente, analizaremos en general cómo las diversas adhesiones religiosas construyen ciudadanía democrática desde su perspectiva familiar y de su participación activa en las iglesias y en las organizaciones de la sociedad civil.

\section{Creyentes “a su manera” y apoyo al sistema democrático}

Respecto a las creencias "a su manera", es importante anotar que generalmente se trata de personas nacidas en un ambiente católico por lo que estamos ante un recorrido interior hacia la disidencia de la cultura dominante. Este camino se confirma cuando se emigra hacia otras iglesias o cuando incrementan el grupo de “creyentes sin religión". De hecho, éstos últimos son católicos nominales nacidos en familias de cultura católica que dicen creer en Dios, Jesucristo y otras verdades, pero no en la Iglesia romana. Este 
tipo de fiel construye su propia visión sincrética combinando sus creencias cristianas con otro tipo de creencias populares o similares, últimamente de corte "postmoderno".

¿Cómo repercuten estas creencias en la visión que se tiene de la democracia y los valores cívico-políticos democráticos? Si acaso hay una actitud de fondo anticultura religiosa oficial, ¿no habrá también una postura antisistema democrático? No resulta fácil responder esta pregunta y menos cuando no tenemos estudios sobre el asunto en América Latina.

En nuestra investigación sobre universitarios en Chile de 2005 nos encontramos con los siguientes datos que nos posibilitan adelantar algunas posibles interpretaciones:

Tabla 10 - Adhesiones religiosas en universitarios y opción democrática. Estudio Universitarios Chilenos, 2005 (\%)

\begin{tabular}{l|ccccc}
\hline \multirow{2}{*}{ Religión } & \multicolumn{4}{|c}{ Régimen de gobierno preferido } \\
\cline { 2 - 5 } & Democrático & Anarquista & Autoritario & Ninguno \\
\hline Católico & 86,0 & 2,2 & 5,4 & 4,2 \\
Católico "a su & 84,3 & 2,6 & 4,5 & 6,6 \\
manera" & 82,1 & 2,5 & 7,3 & 4,3 \\
Evangélico & 79,3 & 4,7 & 4,7 & 8,9 \\
Creyente sin & 74,9 & 2,6 & 4,2 & 16,2 \\
religión & 71,6 & 8,2 & 8,2 & 10,4 \\
Otra religión & 70,1 & 10,7 & 6,9 & 10,4 \\
No creyente & Ateo & &
\end{tabular}

Fuente: Estudio Universitarios Chilenos, 2005. Por el autor. (Fondecyt n. 1040261.)

Estamos aquí ante un fenómeno interesante. Los católicos y los católicos "a su manera" reafirman el valor del sistema democrático. 
Los evangélicos están incluso por sobre el valor medio de $81,2 \%$. Los creyentes "sin religión" están levemente por debajo. Pero lo cierto es que los creyentes en "otras religiones" y los "no creyentes" y "ateos" representan los que con mayor claridad disienten del sistema democrático, ya sea porque lo apoyan menos o porque prefieren “ningún régimen”. Para el caso de los universitarios no creyentes y ateos es claro que dicha afirmación de disidencia de la religiosidad dominante en la sociedad va acompañada por una inclinación por el régimen anarquista $(8,2 \%$ a $10,7 \%$, respectivamente, sobre media de $3,95 \%$ ). Para esta minoría ilustrada es claro que su rebeldía frente a las creencias establecidas se asocia a su rebeldía frente al sistema político establecido.

No es entonces el creyente "a su manera" un disidente del sistema político democrático, tampoco lo son los evangélicos, como veremos más adelante en detalle. Pero ¿qué sucede con las creencias heterodoxas de tipo sincrético, que hemos mencionado y que tejen alternativas religiosas disímiles a los caminos convencionales de las religiones oficiales? ¿Son generadoras de valores y actitudes ciudadanos disidentes?

Tenemos los datos de nuestro estudio sobre universitarios.

\section{Tabla 11 - Ciencias heterodoxas en universitarios y opción democrática. Estudio Universitarios Chilenos, 2005 (\%)}

\begin{tabular}{lcccccc}
\hline \multicolumn{6}{c}{ Régimen de gobierno preferido } \\
\hline & Democrático & Anarquista & Autoritario & Ninguno & Total \\
\hline Cree & 82,8 & 4,4 & 5,0 & 7,9 & $\mathbf{1 0 0}$ \\
No cree & 83,0 & 3,8 & 6,2 & 7,0 & $\mathbf{1 0 0}$ \\
\hline
\end{tabular}

Fuente: Estudio Universitarios Chilenos, 2005. Por el autor.

En el cruce que tenemos en Tabla 11 observamos que el hecho de creer en heterodoxias no condiciona de manera alguna una opción antidemocrática. Prácticamente no influye. 
Estamos hablando aquí de creyentes en verdades cristianas que además afirman creer simultáneamente en al menos ocho o más de las siguientes expresiones: ánimas, maleficios, brujerías, poder de las hierbas, espíritus, la reencarnación, el yoga, la astrología, los fantasmas, los extraterrestres y los chamanes indígenas (machi en la cultura mapuche). Estas creencias heterogéneas no conllevan al rechazo a la democracia aunque se nota una muy leve asociación (no significativa) de los creyentes heterodoxos con el anarquismo y la opción "ningún régimen de gobierno".

Veamos ahora otros cruces acerca de las visiones de la política y de la responsabilidad cívica.

Tabla 12 - Ciencias heterodoxas en universitarios y visiones cívico-políticas. Estudio Universitarios Chilenos, 2005 (\%)

\begin{tabular}{|c|c|c|c|}
\hline & \multicolumn{3}{|c|}{ Visión de la responsabilidad ciudadana } \\
\hline & Positiva & Negativa & Total \\
\hline Cree & 64,0 & 36,0 & 100 \\
\hline \multirow[t]{3}{*}{ No cree } & 61,2 & 38,8 & 100 \\
\hline & \multicolumn{3}{|c|}{ Concepción de la responsabilidad cívica } \\
\hline & Amplia & Política & Total \\
\hline Cree & 73,5 & 26,5 & 100 \\
\hline No cree & 73,4 & 26,6 & 100 \\
\hline \multicolumn{4}{|c|}{ Visión de la política } \\
\hline & Positiva & Negativa & Total \\
\hline Cree & 46,8 & 53,2 & 100 \\
\hline No cree & 49,5 & 50,5 & 100 \\
\hline
\end{tabular}

Fuente: Estudio Universitarios Chilenos, 2005. Por el autor.

Es claro que la información que entregan estos datos va en el sentido de reafirmar la escasa influencia de este tipo de creencias heterodoxas respecto de alternativas antisistema democrático. En 
general hay una visión positiva de la responsabilidad ciudadana y los creyentes heterodoxos analizados tienen una leve mejor opinión de estas responsabilidades. Su visión de un compromiso cívico amplio (por sobre un compromiso cívico que se reduce a las votaciones) no está influida por sus creencias. Aún cuando es importante anotar una leve tendencia de estos creyentes disidentes del catolicismo oficial a ver un poco más negativamente a la política. La asociación es débil pero cualitativamente es significativo que en ambos casos hay una toma de instancia de instituciones oficiales de la sociedad: en el campo religioso (iglesias) y en el campo político (partidos).

Podríamos pensar que los creyentes "a su manera" son creyentes inorgánicos, sujetos autónomos que autogestionan sus producciones de sentido; podríamos pensar que también serían sujetos que afirmarían rasgos libertarios y estarían siendo inorgánicos respecto al sistema político democrático. No es así: los datos entregados por el estudio en universitarios sugieren que esta caracterización calza con una ínfima minoría de gente joven y altamente educada. En general los creyentes "a su manera" son personas integradas al sistema democrático y desarrollan un amplio campo de actividades cívicas.

\section{Evangélicos, integración al mundo y ciudadanía}

Revisemos ahora lo que sucede con los evangélicos. Desde hace muchos años la teoría social le ha concedido crédito a la tesis de que los evangélicos y en especial los pentecostales constituirían un grupo social que por su teología, doctrina y práctica religiosa estarían inclinados hacia posturas sectarias y hacia el conservadurismo en política.

En particular la tesis más refinada (Lalive d'Epinay, 1968) hablaba de la "huelga social" de los evangélicos pentecostales refiriéndose a la tendencia no sólo apolítica y tradicionalista 
observada en ellos, sino que también a su dualismo doctrinario según el cual las tareas del reino humano serían observadas de manera peyorativa dado que lo verdaderamente importante sería la construcción del Reino de Dios.

El mundo evangélico en Chile ha estado sometido a múltiples transformaciones en las últimas décadas. Este no ha sido ajeno a una sociedad que junto con democratizarse se ha ido modernizando y por su crecimiento y progreso económico ha ido generando relevantes niveles de movilidad social. Es sabido que el mundo evangélico - especialmente el pentecostalismo criollo - tuvo su base social (en los inicios del siglo XX y en su trayectoria posterior) en sectores populares, especialmente subproletarios urbanos y campesinos. La "conversión" al Evangelio ha sido estudiada desde el punto de vista social y es claro que estamos frente a un proceso de cambio de vida (desde el alcohol, el desorden de vida familiar y la pobreza) hacia una vida socialmente más austera y elevada. La consecuencia de este proceso ha derivado en una movilidad social ascendente.

En el caso chileno debemos recordar que desde el Golpe Militar de 1973 la mayor parte de las iglesias evangélicas se comprometieron apoyando a la dictadura de Pinochet en la medida en que su orientación doctrinal se dejaba llevar por las consignas anticomunistas de la guerra fría. Pero la historia ha seguido su curso y muchas de las iglesias que abogaban por encontrar un espacio en la sociedad nacional y dejar atrás los días en que se sentían marginadas como minoría religiosa han crecido, se han multiplicado y se han venido integrando cada vez más a la sociedad civil y a los procesos democratizadores, dejando atrás una dinámica sectaria en el sentido de Troeltsch (1931).

No es extraño que numerosos contingentes de evangélicos hayan abandonado la marginalidad debido a la promoción social ganada en sus congregaciones y éstas mismas han ido ganándose su espacio y status en la sociedad. Finalmente los hijos de evangélicos 
- las nuevas generaciones nacidas en la cultura de esas iglesias - han sido los protagonistas de un proceso de integración social que incluso ha significado que muchas nuevas generaciones de evangélicos accedan a niveles educacionales y sociales más elevados que sus padres. Es el caso de los universitarios evangélicos que vienen a representar una elite dentro del mundo evangélico precisamente por ser primera generación que estudia en la educación superior. Ellos constituyen también el semillero de futuros líderes, tanto en el ámbito de sus propias iglesias como en el de la sociedad civil.

Los datos recogidos en una reciente investigación sobre evangélicos en Chile (estudio sobre base de muestra en dos regiones ya mencionado de 2007) nos entregan pistas de interpretación del fenómeno en el sentido de contrarrestar las tesis clásicas respecto al mundo evangélico y al mismo tiempo entregarnos un conjunto de indicaciones relativas a cómo los evangélicos están enfrentando la construcción de lo político y de la sociedad civil en un contexto de construcción democrática.

En primer lugar hay 78\% de evangélicos que están muy de acuerdo o de acuerdo con la siguiente afirmación: "El derecho a la ciudadanía es fundamental para el desarrollo democrático del país".

Tabla 13 - Evangélicos 2007: el derecho a la ciudadanía es fundamental para el desarrollo democrático del país (\%)

\begin{tabular}{l|c|c|c|c|c}
\hline \multicolumn{1}{c|}{ Educación } & $\begin{array}{c}\text { Total } \\
\text { acuerdo }\end{array}$ & Acuerdo & $\begin{array}{c}\text { Neutro }+ \\
\text { desacuerdo }\end{array}$ & $\begin{array}{c}\text { No } \\
\text { sabe }\end{array}$ & Total \\
\hline Básica 1er nivel & 39,1 & 43,5 & 8,7 & 8,7 & $\mathbf{1 0 0}$ \\
Básica 2do nivel & 25,3 & 46,0 & 14,9 & 13,8 & $\mathbf{1 0 0}$ \\
$\begin{array}{l}\text { Media incom- } \\
\text { pleta }\end{array}$ & 27,6 & 48,3 & 12,1 & 12,1 & $\mathbf{1 0 0}$ \\
$\begin{array}{l}\text { Media completa } \\
\text { Técnica }\end{array}$ & 26,3 & 50,4 & 14,3 & 9,0 & $\mathbf{1 0 0}$ \\
Universitaria & 29,1 & 44,7 & 16,5 & 9,7 & $\mathbf{1 0 0}$ \\
\hline
\end{tabular}

Fuente: Investigación Fondecyt n. 1060988. 
Según el cruce por nivel educacional observamos que, en los extremos de menor educación (analfabetos y educación básica primer nivel) y universitarios, por el otro lado, hay mayor apoyo a la idea de que los derechos ciudadanos son fundamentales para el régimen democrático. En los niveles medios de educación los evangélicos chilenos revelan mayor distancia o ignorancia.

Consultados acerca de la relación entre ciudadanía y voto, 58\% declara estar de acuerdo con la afirmación: "La ciudadanía no es completa si no se ejerce el derecho a voto", mientras que $14 \%$ la rechaza.

Los evangélicos de mayores niveles educativos, especialmente técnicos y universitarios, tienden a estar menos de acuerdo con esta afirmación toda vez que los evangélicos han comenzado a comprender que su labor en el mundo es relevante y que ellos tienen algo que decir en la construcción de la sociedad civil, más allá del ejercicio del derecho a votar.

En este sentido hay una crítica a la política y a la sociedad política pero que no es contraria a la sociedad democrática, sino que está ensayando nuevos caminos para una ciudadanía social y cultural.

Esta voluntad de inserción en el mundo viene a contradecir la teología dualista que clásicamente los alejaba del pecado y de las "cosas mundanas". Si bien todavía persiste una mentalidad recelosa de las cosas del mundo, con el incremento de los niveles educativos, los evangélicos se van dando a la idea de que deben incorporarse de pleno a la sociedad civil. 
Tabla 14 - Evangélicos 2007: un cristiano no debe mezclarse para nada en los asuntos mundanos (\%)

\begin{tabular}{l|ccccc}
\hline \multicolumn{1}{c|}{ Educación } & Acuerdo & Neutro & Desacuerdo & Total \\
\hline Básica 1er nivel & 73,9 & 21,7 & 4,3 & $\mathbf{1 0 0}$ \\
Básica 2do nivel & 52,8 & 22,5 & 24,7 & $\mathbf{1 0 0}$ \\
Media incompleta & 54,1 & 23,0 & 23,0 & $\mathbf{1 0 0}$ \\
Media completa & 34,8 & 30,3 & 34,8 & $\mathbf{1 0 0}$ \\
Técnica & 51,5 & 22,3 & 26,2 & $\mathbf{1 0 0}$ \\
Universitaria & 38,8 & 20,0 & 41,3 & $\mathbf{1 0 0}$ \\
\hline
\end{tabular}

Fuente: Investigación Fondecyt n.1060988.

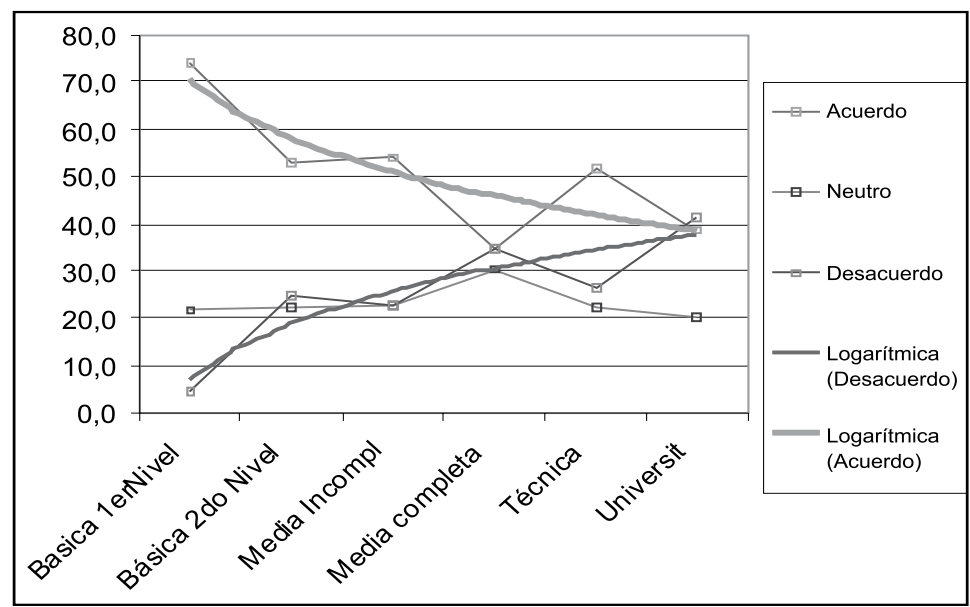

Fuente: Investigación Fondecyt n.1060988.

\section{Gráfico 1. Un cristiano no debe mezclarse en asuntos mundanos.}

Efectivamente, todavía hay evangélicos que se adhieren a una doctrina cristiana dualista, que propicia el abstencionismo en el campo político. Ellos están presentes en estratos con menores niveles de escolaridad. 
Sin embargo, como se observa claramente en el gráfico, a medida que nos elevamos en los niveles de escolaridad se da la tendencia a negar la clásica teología dualista sectaria que alejaba a los evangélicos de participar en actividades cívicas y políticas.

Recordemos que de hecho los evangélicos están elevando sus niveles de escolaridad por lo que previsiblemente estaríamos presenciando un proceso de "acomodo al mundo" y por ende de salida de situación de secta y de ingreso a situación de "iglesia" que contemporiza con la sociedad según la tipología clásica de Troeltsch (1931). Todo ello por cierto es una buena noticia para la sociedad civil y para la democracia en la medida en que los evangélicos se incorporan como una fuerza creciente que construye capital social y redes que tejen ciudadanía democrática.

Como vemos, los evangélicos están mucho más dispuestos a participar en diversas instancias de la sociedad civil que a participar directamente en política.

Tabla 15 - Evangélicos 2007: la ciudadanía es una responsabilidad que todos debemos asumir (\%)

\begin{tabular}{l|c|c|c|c}
\hline \multicolumn{1}{c|}{ Educación } & Acuerdo & $\begin{array}{c}\text { Neutro }+ \\
\text { desacuerdo }\end{array}$ & No sabe & Total \\
\hline Básica 1er nivel & 78,3 & 8,7 & 13,0 & $\mathbf{1 0 0}$ \\
Básica 2do nivel & 72,7 & 13,6 & 13,6 & $\mathbf{1 0 0}$ \\
Media incompleta & 81,0 & 6,9 & 12,1 & $\mathbf{1 0 0}$ \\
Media completa & 76,7 & 15,0 & 8,3 & $\mathbf{1 0 0}$ \\
Técnica & 74,8 & 18,4 & 6,8 & $\mathbf{1 0 0}$ \\
Universitaria & 86,1 & 13,9 & 0 & $\mathbf{1 0 0}$ \\
\hline
\end{tabular}

Fuente: Investigación Fondecyt n. 1060988.

En primer lugar, los evangélicos del siglo XXI están conscientes de que deben asumir la ciudadanía. Así lo afirman 78\%. 
En segundo lugar, los evangélicos están muy dispuestos a ocupar espacios e incluso cargos en la sociedad civil, como vemos.

Tabla 16 - Evangélicos 2007: participación en organizaciones

\begin{tabular}{l|c|c|c}
\multicolumn{4}{c}{ vecinales (\%) } \\
\hline Educación & Siempre & $\begin{array}{c}\text { Pocas veces / } \\
\text { nunca }\end{array}$ & Total \\
\hline Básica & 24,8 & 75,2 & $\mathbf{1 0 0}$ \\
Media & 22,2 & 77,8 & $\mathbf{1 0 0}$ \\
Superior & 20,7 & 79,3 & $\mathbf{1 0 0}$ \\
Total & $\mathbf{2 2 , 2}$ & $\mathbf{7 7 , 8}$ & $\mathbf{1 0 0}$ \\
\hline
\end{tabular}

Fuente: Investigación Fondecyt n.1060988.

Un significativo $22 \%$ participa regularmente en organizaciones vecinales siendo incluso los evangélicos de menor educación, los que están comprometidos en barrios populares los que lo hacen en mayor proporción.

Tabla 17 - Evangélicos 2007: estudio dos regiones RM y IX (\%)

\begin{tabular}{lcccc}
\hline & \multicolumn{3}{c}{ Participar en campaña } \\
\hline & Política & Medio ambiental & Derechos humanos \\
\hline Básica & 3,3 & 45,8 & 43,6 \\
Media & 4,7 & 44,8 & 46,3 \\
Superior & 10,3 & 54,7 & 50,2 \\
Total & $\mathbf{6 , 5}$ & $\mathbf{4 8 , 8}$ & $\mathbf{4 7 , 2}$ \\
\hline
\end{tabular}

Fuente: Investigación Fondecyt n. 1060988.

Es claro que los evangélicos comparten la distancia que en general la sociedad demuestra hacia la política de partidos $\mathrm{y}$, sin embargo, 6,5\% declara que estaría dispuesto a participar 
en una campaña política. En cambio hay una mayor proporción de evangélicos que estaría dispuesto a participar en campañas de defensa del medio ambiente (49\%) y/o de defensa de los derechos humanos (47\%).

Como se observa, en todos los casos crece la proporción de evangélicos con mayor educación que tiende a estar disponible para participar en estas actividades que dicen relación con ámbitos claves de construcción democrática en la época actual.

Respecto a la actividad política, propiamente tal, si bien no recibe todas las preferencias, no es menos cierto que tampoco se da un rechazo total al sistema partidario y a la posibilidad de aportar a este quehacer sociopolítico.

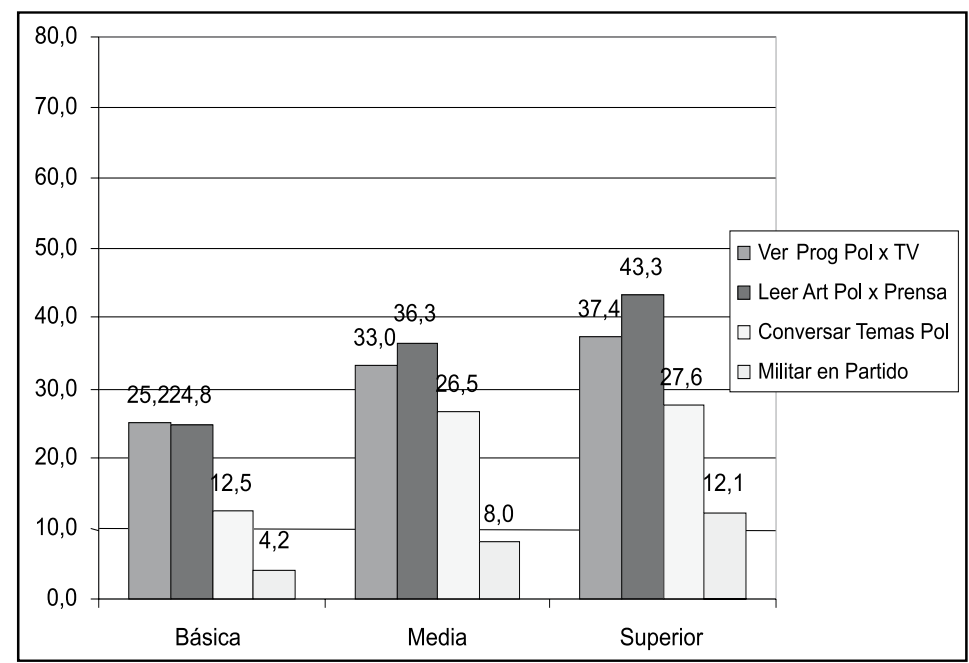

Fuente: Investigación Fondecyt n.1060988.

\section{Gráfico 2. Interés por la política según escolaridad (Estudio Evangélicos, dos regiones, 2007).}

Si observamos el Gráfico 2, veremos que no menos de un tercio de los evangélicos declara interés por ver programas políticos 
en la televisión; a medida que se crece en nivel educativo, crece éste interés. Un porcentaje mayor $(36,4 \%)$ declara interés por leer artículos políticos en la prensa, siendo mayor éste interés en niveles educativos medios y superiores; un porcentaje menor declara interés por conversar temas políticos $(23,8 \%)$, siendo menor este ejercicio entre los menos educados y, finalmente, un menor porcentaje declara interés en militar en un partido político: $8,7 \%$, siendo menor todavía éste interés entre los de menor nivel educativo (4,2\%).

Todo indica, pues, que los evangélicos chilenos encuestados en el año 2007 no rechazan sino que aceptan la actividad política incluso la de los partidos y al menos un tercio de ellos está abierto a escuchar, ver o leer noticias políticas y cerca de un cuarto conversa sobre ello. Todo esto ha de interpretarse a la luz del hecho de que la opinión pública chilena tiende a ver en la política de partidos una actividad poco honesta, asechada por los riesgos de la corrupción, la demagogia, la desunión, y el propio interés.

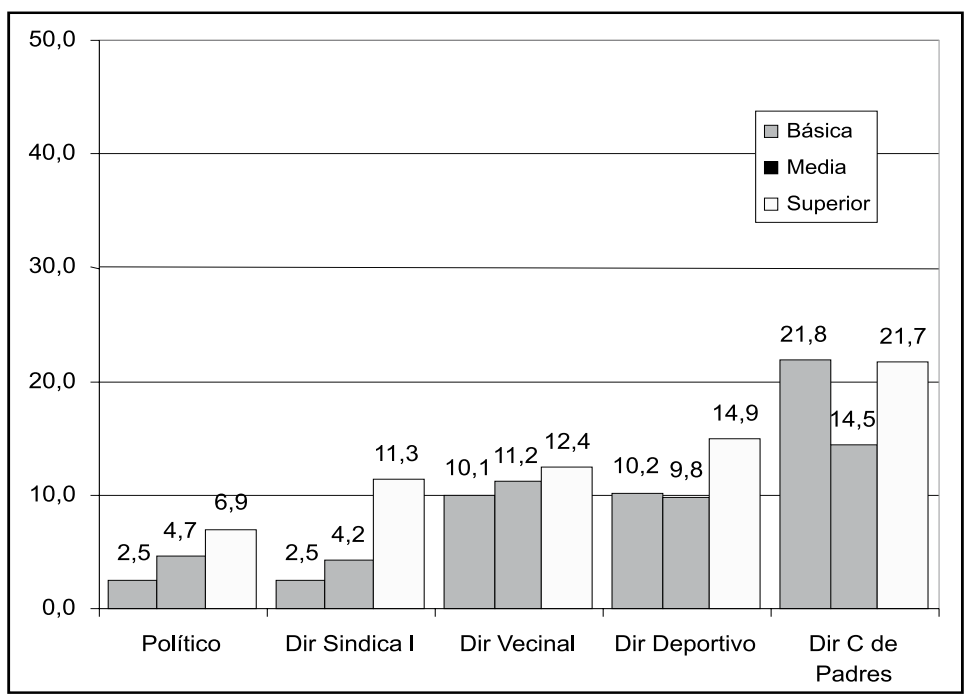

Fuente: Investigación Fondecyt n. 1060988.

\section{Gráfico 3. Ser candidato a... según escolaridad (Estudio Evangélicos, 2007).}


Los evangélicos chilenos están disponibles para asumir incluso muchas funciones de representación en diversas instancias de la sociedad civil. Si bien la política partidaria, como hemos dicho, no recibe interés mayoritario, es interesante anotar que entre los evangélicos hay más de 5\% dispuesto a participar activamente en tanto que candidato, de esta actividad. En seguida los evangélicos serían candidatos a cargos sindicales $(6,5 \%)$, cargos en organizaciones vecinales $(11,4 \%)$, asociaciones deportivas $(11,8 \%) \mathrm{y}$, por cierto, asociaciones de centros de padres y apoderados en las escuelas $(18,8 \%)$. El gráfico es explícito al establecer una relación creciente y directa entre nivel educativo y voluntad de participación en la dirigencia de asociaciones de la sociedad civil. Nuevamente el factor educacional en su influencia hacia las adhesiones religiosas, en este caso, evangélicas, posibilita comprender que la dinámica previsible, en caso de continuar incrementándose los niveles educativos, es que los evangélicos tengan una mayor inserción en actividades de construcción de nuevas formas de interacción ciudadana en la sociedad en vías de desarrollo.

En este sentido, no es posible responder taxativamente si con el incremento de los niveles de escolarización significará una disminución del crecimiento de los evangélicos en las nuevas generaciones o si bien ello significará un cambio en los padrones de inserción y aporte de los evangélicos a la construcción de una ciudadanía activa. Pero al menos sí parecen estar actuando estas dos tendencias en la dinámica observada y probablemente lo que sucede sea una combinación de ambas.

\section{Adhesiones religiosas plurales y participación en la construcción de ciudadanía democrática}

Hemos visto cómo los católicos y los evangélicos tienden a participar en la vida cívica y cómo, en cambio, los menos creyentes 
y ateos tienden a afirmar con menor convicción y peso los valores de una ciudadanía democrática. ¿Qué sucede con los creyentes practicantes y especialmente con los católicos en una perspectiva comparada en el marco de la diversidad plural de adhesiones religiosas?

Estudios comparativos desarrollados en muestras de población general en cuatro regiones de Chile y en grupos de familias católicas a nivel nacional nos ayudarán a levantar ciertas hipótesis e interpretaciones acerca de cómo las diversas adhesiones religiosas construyen ciudadanía democrática. Sobre todo analizaremos la perspectiva familiar, la participación activa en las iglesias y la participación en diversas organizaciones de la sociedad civil.

\section{a) Religión, familia y socialización ciudadana}

Revisemos ahora lo que sucede de parte de las propias instituciones sociales y religiosas en términos de sus roles socializadores, especialmente la familia como agente de socialización religiosa y cívica primordial. Se preguntó acerca de cómo veían este rol, las diversas adhesiones y se analiza en el cruce por nivel educativo.

Los evangélicos son los que más declaran su acuerdo con la afirmación: "La familia es la primera escuela de educación del ciudadano" (80,6\%); le siguen los católicos $(74,6 \%)$ y en tercer lugar los que adhieren a "otra religión" (63,8\%) y los "ateos" $(63,8 \%)$.

De acuerdo al cruce por nivel educacional observamos que en el caso de los católicos a mayor nivel educacional relativo una leve tendencia favorable a confirmar la afirmación. Igual tendencia encontramos entre los adherentes de otras religiones. 
Tabla 18 - La familia es la primera escuela de educación del ciudadano $(\%)$

\begin{tabular}{|c|c|c|c|c|}
\hline \multicolumn{3}{|c|}{ Católicos } & \multirow[t]{2}{*}{ Total } & \multirow{2}{*}{$\begin{array}{c}\text { Acuerdo } \\
\text { sumatoria } \\
\text { x religión } \\
74,6\end{array}$} \\
\hline Nivel educativo & Total acuerdo & $\begin{array}{l}\text { Menor acuerdo } \\
\text { / desacuerdo }\end{array}$ & & \\
\hline Básico & 71,4 & 28,6 & 100 & \\
\hline Medio / Alto & 79,7 & 20,3 & 100 & \\
\hline \multicolumn{5}{|c|}{ Evangélicos } \\
\hline Nivel educativo & Total acuerdo & $\begin{array}{c}\text { Menor acuerdo } \\
\text { / desacuerdo }\end{array}$ & & 80,6 \\
\hline Básico & 81,5 & 18,5 & 100 & \\
\hline Medio / Alto & 75,0 & 25,0 & 100 & \\
\hline \multicolumn{5}{|c|}{ Otra religión } \\
\hline Nivel educativo & Total acuerdo & $\begin{array}{c}\text { Menor acuerdo } \\
\text { / desacuerdo }\end{array}$ & & 63,8 \\
\hline Básico & 59,1 & 40,9 & 100 & \\
\hline Medio / Alto & 66,7 & 33,3 & 100 & \\
\hline \multicolumn{5}{|c|}{ Ateos } \\
\hline Nivel educativo & Total acuerdo & $\begin{array}{l}\text { Menor acuerdo } \\
\text { / desacuerdo }\end{array}$ & & 63,8 \\
\hline Básico & 100 & 0 & 100 & \\
\hline Medio / Alto & 61,5 & 38,5 & 100 & \\
\hline
\end{tabular}

Fuente: Estudio Religión y Familia, 2005, muestra aleatoria de cuatro regiones de Chile central: La Serena, Valparaíso, Rancagua y Metropolitana. Estudio del autor $(\mathrm{N}=$ 411). 
Entre los evangélicos la tendencia es a la inversa: mientras menor educación, mayor tendencia relativa a reafirmar a la familia en su rol de educadora para la ciudadanía. Esto podría explicarse dado el hecho de que la religión evangélica tiende a centrar el rol educador general en la familia, concediendo menor importancia a las instancias formas educativas fuera del hogar. En este caso sería importante indagar con mayor profundidad qué se entiende por "formación ciudadana”. En un sentido más ilustrado, como podría serlo el de aquellas personas con mejores niveles educativos, la formación ciudadana no se reduce a buenos comportamientos y respeto a las leyes sino que va más allá e incluye conocimientos básicos acerca del sistema político democrático y de la responsabilidad ciudadana en su funcionamiento.

Es un buen indicador el hecho de que $80 \%$ de los evangélicos declaren que en sus familias está la responsabilidad de formar ciudadanos. Se trata de una postura que contribuye, desde su perspectiva, con la responsabilidad en la construcción de la sociedad civil y política. Pero los indicios nos sugieren que el concepto de "ciudadanía" subyacente bien podrá ser bastante elemental.

En el caso de los católicos, otros estudios nos han indicado que las familias católicas confían bastante en sus propias capacidades formadoras pero también confían en las escuelas, más todavía cuando ellas son escuelas católicas o bien escuelas fiscales de prestigio y a las cuales el católico medio tiene acceso.

En el caso de los adherentes a "otras" religiones (que incluye a mormones, testigos de Jehová, adventistas y creyentes sin religión, entre otros), no queda claro si su menos entusiasta afirmación de que es la familia la que debe formar ciudadanía tiene que ver con su confianza en otras instituciones de formación cívica, o bien, por el contrario, en su desconfianza de lo que significa "formar ciudadanos", lo que revelaría una sutil desconfianza hacia las "cosas del mundo". 
En el caso de los "ateos", es clara su menor opción por la familia como agente socializadora de valores cívicos, posiblemente dado que la cultura "atea" está más ligada en la historia cultural chilena con corrientes laicistas que han puesto mucho acento en el rol formador de la escuela como primera instancia de ciudadanía.

\section{b) Participación en organizaciones religiosas y participación ciudadana}

¿Cómo se reflejan las diversas opciones religiosas, sobre todo en la perspectiva de su participación en organizaciones religiosas y en su "práctica" religiosa en relación al apoyo y participación en organizaciones de la sociedad civil? Una hipótesis interpretativa plausible sería que a mayor grado de participación y práctica religiosa habría una menor participación en organizaciones sociales, sobre todo por el hecho de que el tiempo de dedicación a las diversas actividades es escaso, en contextos de vida urbana, familiar y laboral altamente exigentes y competitivos.

En contradicción con la interpretación anterior, nuestros estudios de los años 2005 (en una muestra general) y 2007 (en una muestra de evangélicos) indican que, aunque con diferencias, los practicantes tienden a participar un poco más que los no practicantes en la mayoría de las organizaciones de la sociedad civil. Esto es así con ciertas excepciones como los clubes deportivos, sindicatos y partidos políticos para evangélicos y los clubes deportivos para la muestra intencional de católicos a nivel nacional en el estudio de 2005. 


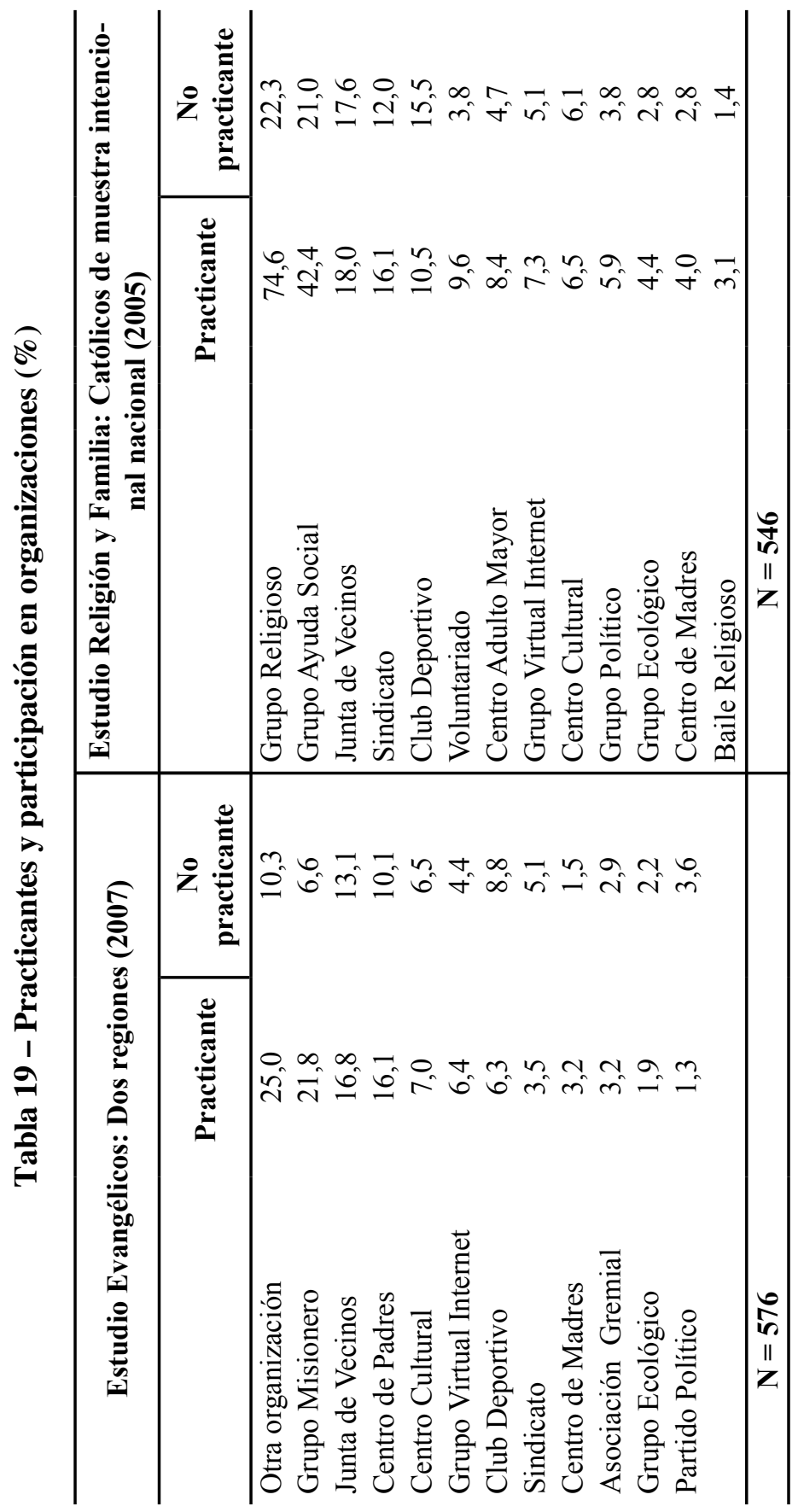


En general, el hecho de ser un fiel activo en actividades en su iglesia no le inhibe de participar en otro tipo de actividades y agrupaciones sociales. En el caso de los evangélicos los practicantes participan plenamente, incluso en una mayor proporción que el ciudadano común, de organizaciones territoriales locales y vecinales: juntas de vecinos, centros de padres y apoderados, centros culturales, centros de madres, pero tampoco se restan de organizaciones propias de la sociedad de la información grupos virtuales de Internet. En cuanto a organizaciones funcionales, los evangélicos también participan pero en menor proporción: sindicatos, grupos ecológicos, partidos políticos.

En el caso de muchas iglesias evangélicas, varias de ellas pentecostales, el alto grado de compromiso en actividades misioneras inhibe de una mayor participación en grupos de tipo sindical, político o deportivo, pero ciertamente no en grupos de ayuda social y caridad.

En el caso de los católicos, la muestra intencional de familias católicas a nivel nacional, de 2005, nos indica que los católicos practicantes, que van al menos tres veces a misa al mes, participan también de manera elevada en actividades de la iglesia y ello no les inhibe de participar activamente en una variada gama de organizaciones y asociaciones de la sociedad civil, incluyendo territoriales y funcionales: ayuda social, junta de vecinos, sindicatos, voluntariados, grupos políticos, ecológicos, etc. Todo ello en mucho mayor proporción que el "católico no practicante" que proporcionalmente participa más solamente en clubes deportivos.

La doctrina social católica desarrollada con mayor intensidad desde la segunda mitad del siglo XX y la historia del catolicismo comprometido desde las Conferencias de Obispos de Medellín (1968) en adelante hasta Aparecida (2007) han calado en el sentido del compromiso de los católicos, más allá de sus preferencias 
políticas e ideologías, traduciéndose en un estímulo para que la participación en parroquias y comunidades se potencie y proyecte hacia la participación activa en organizaciones de construcción de la sociedad civil en el marco de la construcción democrática.

Durante muchos años, en cambio, los evangélicos, en sus vertientes pentecostales, centraron su participación en actividades propias de sus congregaciones y no se proyectaron mayormente hacia organizaciones de la sociedad civil salvo en materias de caridad y promoción social. Este panorama, como se observa, está cambiando y si bien no encontramos un patrón semejante a los católicos, al menos encontramos un mundo evangélico mucho más comprometido con organizaciones propias de la sociedad civil local que antes.

Una muestra en cuatro regiones del Chile central, del estudio de 2005 sobre Religión y Familia, nos permite comparar patrones de comportamiento entre evangélicos y católicos y otras adhesiones. 
Tabla 20 - Participación en organizaciones según adhesión religiosa $(\%)$

\begin{tabular}{|c|c|c|c|c|}
\hline & Practicante & $\begin{array}{c}\text { No } \\
\text { practicante }\end{array}$ & Practicante & $\begin{array}{c}\text { No } \\
\text { practicante }\end{array}$ \\
\hline & \multicolumn{2}{|c|}{ Junta de Vecinos } & \multicolumn{2}{|c|}{ Centro Cultural } \\
\hline Católico & 26 & 25 & 7,3 & 5,8 \\
\hline Evangélico & 17,4 & 37,5 & 4,3 & 0 \\
\hline Bíblica & 22,2 & 40 & 0 & 0 \\
\hline Creyente & 0 & 11,6 & 0 & 11,6 \\
\hline \multirow[t]{2}{*}{ Ateo } & 0 & 16,7 & 0 & 25 \\
\hline & \multicolumn{2}{|c|}{ Grupo Religioso } & \multicolumn{2}{|c|}{ Grupo Político } \\
\hline Católico & 34,1 & 8,1 & 4,9 & 6,4 \\
\hline Evangélico & 52,2 & 25 & 4,3 & 0 \\
\hline Bíblica & 33,3 & 40 & 0 & 0 \\
\hline Creyente & 0 & 2,3 & 0 & 4,7 \\
\hline \multirow[t]{2}{*}{ Ateo } & 0 & 0 & 0 & 29,2 \\
\hline & \multicolumn{2}{|c|}{ Grupo Virtual Internet } & \multicolumn{2}{|c|}{ Voluntariado } \\
\hline Católico & 4,9 & 3,5 & 8,9 & 2,9 \\
\hline Evangélico & 4,3 & 0 & 4,3 & 0 \\
\hline Bíblica & 22,2 & 0 & 11,1 & 0 \\
\hline Creyente & 100 & 14 & 0 & 2,3 \\
\hline \multirow[t]{2}{*}{ Ateo } & 0 & 8,3 & 0 & 4,2 \\
\hline & \multicolumn{2}{|c|}{ Sindicato o gremio } & \multicolumn{2}{|c|}{ Grupo Ecológico } \\
\hline Católico & 7,3 & 11 & 0 & 0,6 \\
\hline Evangélico & 21,7 & 12,5 & 4,3 & 0 \\
\hline Bíblica & 11,1 & 0 & 0 & 0 \\
\hline Creyente & 50 & 4,7 & 0 & 4,7 \\
\hline \multirow[t]{2}{*}{ Ateo } & 0 & 20,8 & 0 & 20,8 \\
\hline & \multicolumn{2}{|c|}{ Grupo de Ayuda Social } & \multicolumn{2}{|c|}{ Centro de Madres } \\
\hline Católico & 17,1 & 13,4 & 6,5 & 2,9 \\
\hline Evangélico & 26,1 & 12,5 & 4,3 & 12,5 \\
\hline Bíblica & 33,3 & 20 & 0 & 0 \\
\hline Creyente & 0 & 11,6 & 0 & 2,3 \\
\hline \multirow[t]{2}{*}{ Ateo } & 0 & 4,2 & 0 & 0 \\
\hline & \multicolumn{2}{|c|}{ Club Deportivo } & \multirow{6}{*}{\multicolumn{2}{|c|}{$\begin{array}{l}\text { Fuente: Estudio sobre Religión y } \\
\text { Familia, 2005. Investig- } \\
\text { ación del autor. }\end{array}$}} \\
\hline Católico & 10,6 & 17,4 & & \\
\hline Evangélico & 30,4 & 25 & & \\
\hline Bíblica & 22,2 & 0 & & \\
\hline Creyente & 0 & 11,6 & & \\
\hline Ateo & 0 & 12,5 & & \\
\hline
\end{tabular}


Como resulta coherente, los simples "creyentes en un ser superior" y los "ateos" no son practicantes.

Se observa que la tendencia general es a que los practicantes de todas las opciones religiosas tienden a ser también activos ciudadanos: participan en variadas organizaciones de la sociedad civil, desde juntas de vecinos, sindicatos, ayuda social voluntariados, centros de madres, grupos virtuales, grupos ecológicos, grupos políticos, etc. y en algunos casos, no en todos por cierto, los creyentes practicantes son más activos en su participación que los no practicantes, lo cual confirma las observaciones anteriores.

\section{c) Adhesiones religiosas y valor cívico de respeto a la autoridad}

En general es importante preguntarse acerca de la adhesión a la autoridad y a las normas institucionales en la sociedad. Es un tema central en la comprensión de la proyección de la responsabilidad cívica en la construcción democrática y la forma como las doctrinas religiosas sobre la autoridad se han planteado este punto es de gran relevancia. No nos interesa en este estudio un análisis de las doctrinas eclesiales o de los enfoques o querellas teológicas, sino una mirada hacia la mentalidad de los fieles y la forma como en el lenguaje del sentido común se representa la relación con la autoridad.

Para situar el tema, es necesario recordar que muchas iglesias han nacido como un grupo de tendencia sectaria que ha roto con las normas de la religión y de la cultura dominante. Su voluntad de construcción de un "reino de Dios" en la tierra le ha llevado incluso a confrontarse con los poderes establecidos. Es sabido, por otra parte, que en la teología de la Reforma el pensamiento de San Pablo, así como de varios Padres de la Iglesia, juegan un papel principal. Entre los textos del apóstol, la epístola a los Romanos ocupa un lugar destacadísimo tanto en la teología de Lutero como de Calvino (Carvajal, 2000). 
En la epístola a los Romanos 13, 1-7, San Pablo fija los principios de la ética cristiana: "Sométanse todos a las autoridades constituidas, pues no hay autoridad que no provenga de Dios, y las que existen, por Dios han sido constituidas. De modo que, quien se opone a la autoridad, se rebela contra el orden divino, y los rebeldes se atraerán sobre sí mismos la condenación”. Es sabido, sin embargo, que el texto es más amplio y las ideas más profundas, de modo que se establece aquí el principio de legitimidad y de respeto a la autoridad, como asimismo los criterios de juicio que los teólogos y líderes eclesiales han barajado para fundamentar el derecho a la resistencia a una autoridad inicua.

¿Qué hay de este principio de respeto a la autoridad entre los creyentes latinoamericanos de hoy?

Los datos del Latinobarómetro nos hablan de que, en general, existe una opinión mayoritaria que acepta la idea de que los ciudadanos debieran ser más activos en cuestionar a los líderes y en el cruce por religión, no existe entre las diversas adhesiones religiosas tendencias muy pronunciadas, aún cuando hay algunas diferencias.

\section{Tabla 21}

\begin{tabular}{lc|c|c|c}
\hline \multicolumn{5}{c}{ A la autoridad hay que } \\
\hline & $\begin{array}{c}\text { Cuestionar } \\
(\mathbf{\%})\end{array}$ & $\begin{array}{c}\text { Respetar } \\
(\%)\end{array}$ & No responde & Total \\
\hline Católica & 54,6 & 41,3 & 4,1 & $\mathbf{1 0 0}$ \\
Evangélica & 49,5 & 46,9 & 3,6 & $\mathbf{1 0 0}$ \\
Pentecostal & 57,7 & 36,6 & 5,7 & $\mathbf{1 0 0}$ \\
Protestante & 52,9 & 44,9 & 2,2 & $\mathbf{1 0 0}$ \\
Bíblica & 46,9 & 49,2 & 3,9 & $\mathbf{1 0 0}$ \\
Otra & 59,9 & 37,5 & 2,6 & $\mathbf{1 0 0}$ \\
Sin religión & 57,4 & 36,1 & 6,5 & $\mathbf{1 0 0}$ \\
Ateo & 74,3 & 23,0 & 2,7 & $\mathbf{1 0 0}$ \\
\hline
\end{tabular}

Fuente: Latinobarómetro, 2006. Tabulación propia. 
En efecto, se preguntó si se estaba de acuerdo con las siguientes afirmaciones: de acuerdo con "Deberíamos ser más activos en cuestionar a nuestros líderes" o bien, de acuerdo con "Como ciudadanos deberíamos mostrar más respeto por la autoridad". Los resultados fueron: la media de "cuestionar" 54,3\% y de "respetar" $41,5 \%$. Es interesante anotar que los católicos se mueven en torno a la media; que los evangélicos y mucho más los bíblicos se inclinan, relativamente hablando, en forma leve por respetar la autoridad, los pentecostales levemente por cuestionarla, así como los "sin religión" y "otra religión". Los ateos son los únicos que se inclinan mucho más acentuadamente por "cuestionar a nuestros líderes".

Los evangélicos del estudio de 2006, a nivel latinoamericano, demuestran así que la prédica de Romanos que hemos citado y que legitima la sumisión acrítica a la autoridad establecida, leída en forma literal - como de hecho lo fuese durante muchos años por parte de las principales confesiones evangélicas chilenas que apoyaron al Régimen de Pinochet (Lagos, 1988) - ha sido dejada de lado.

Una nueva interpretación - a nivel del sentido común de los ciudadanos latinoamericanos, incluidos los que adhieren fuertemente a confesiones religiosas - del "respeto a la autoridad" parece extenderse y que toma en consideración la posibilidad de una actitud reflexiva en la obligación en conciencia de los mandatos de la autoridad y ya no la obediencia ciega a una autoridad legitimada extra-socialmente por argumentos sacralizantes. Todo ello nos habla de una conciencia social ciudadana, ilustrada, democrática y ciertamente más secularizada en este aspecto, pero que no necesita despojarse de sus creencias para afirmar una forma de ciudadanía activa y crítica.

Es interesante anotar que incluso en el caso de los pentecostales se da esta tendencia. Ellos y los "sin religión", presumiblemente por razones con fundamentos bastante diversos, tienden a aceptar una actitud crítica hacia las autoridades y líderes. En todo caso, estamos 
muy distantes de una mayoritaria sumisión incondicional hacia los líderes que mostraban muchos adherentes del pentecostalismo hace no menos de tres décadas atrás, en muchas naciones y rincones de América Latina. Todo esto no quiere decir, necesariamente, que no subsistan prácticas autoritarias y/o paternalistas, al interior de las relaciones jerárquicas, en el seno de muchas comunidades y congregaciones de las iglesias.

\section{Conclusión: ¿Pluralismo religioso y nueva ciudadanía?}

El origen del concepto de ciudadanía está históricamente ligado al intento por establecer un marco de acción a la vida política, estableciendo un orden seguro para la vida de los habitantes de la unidad política.

En la ciudad-estado griega la ciudadanía era emancipación de los lazos de parentesco e incorporación voluntaria a una comunidad de habitantes de la polis. Para Weber (1998) la asociación entre ciudadanía y libertad, que surge desde la tradición griega, se desarrolla en las ciudades medievales y se consolida con la Revolución Francesa, supone un proceso de secularización. La disolución de los lazos mágicos o religiosos que sancionaban la relación entre los individuos y su división social es fundamental para permitir la libre asociación y solidaridad entre los ciudadanos de una comunidad determinada.

El judaísmo antiguo y su crítica a la magia, la doctrina paulista de incorporar judíos y gentiles a la comunidad de salvados y el protestantismo han contribuido a derribar las barreras mágicas entre clanes, tribus y pueblos, haciendo posible con la emergencia de la convivencia en la ciudad - el burgo medieval y sus gremios - la universalización del concepto de ciudadano que anteriormente fuese muy restrictivo a ciertos grupos sociales de propietarios y poderosos. 
Desde este punto de vista, tanto la ciudadanía como el pluralismo y la diversidad actual han surgido como procesos y conceptos que atentan contra el orden religioso y su desarrollo ha sido posibilitado por los procesos de secularización.

En el contexto chileno y latinoamericano los procesos de crecimiento, modernización e integración a la sociedad global han incrementado las variables secularizadoras. Los procesos políticos vividos durante las últimas décadas han transformado la antigua relación entre religión y política y las propias transformaciones del campo religioso han abierto la puerta a una serie de procesos diversos entre ciudadanía y religión.

Pero al contrario de las clásicas teorías weberianas del "desencantamiento del mundo" (Weber, 1969) las expresiones religiones no han desaparecido, se han diversificado y todavía constituyen una fuente de sentido para los ciudadanos chilenos y latinoamericanos. Pero la trayectoria de los procesos secularizadores en nuestro contexto histórico ciertamente no ha ido, ni irá, por los senderos trazados por la reforma protestante con su discurso ascético y su idea de profesión.

Las grandes transformaciones culturales provocadas por la globalización de las últimas décadas han impactado en suelo latinoamericano con sellos propios pero no han evitado que en estas regiones se dé, de manera característica con rasgos propios, lo que se ha llamado una cultura que va superando los marcos de la modernidad, esto es, una cultura "postmoderna". En estas nuevas condiciones culturales, en este continente, la transformación del sistema hacia una cultura postmoderna ha garantizado la renovación de valores antiguos en las nuevas condiciones, lo que Debray ha llamado "el arcaísmo postmoderno" (Debray, 1996). De este modo observamos cómo en las generaciones jóvenes la religión subsiste y se combina de manera no ortodoxa ni convencional con diversas formas de racionalización de la vida. 
En el contexto cultural "latino" las transformaciones educativas (el aumento de los niveles educativos, el acceso a las instituciones de educación superior, los cambios en la pedagogía y la renovación de los modelos convencionales, y la apertura a las nuevas tecnologías y la ciencia) conducen a la autonomía de un sujeto "latino" y simultáneamente "postmoderno" que indaga "a su manera" los nuevos modos de creer. Ello explica, al menos parcialmente, por qué la educación y la racionalidad que genera inducen a la desconfianza de las instituciones religiosas (y sus dogmas) aún cuando no llevan al cuestionamiento de la religión y de las búsquedas espirituales.

Analizando el conjunto de datos que hemos entregado en este trabajo, podemos concluir que no existen, en efecto, patrones determinados, ni deterministas, en el desarrollo de la relación religión y política, religión y ciudadanía democrática, lo cual ya es un gran acontecimiento que nos indica que estamos ante un panorama radicalmente distinto al que predominaba durante buena parte del siglo XX.

De hecho no es posible afirmar que exista, por una parte, una tendencia al conservadurismo de parte de los católicos, por el contrario es evidente el pluralismo; como de otra parte, los evangélicos y pentecostales ya parecen haber dejado atrás (Freston, 1994), en lo sustancial, la tendencia a privilegiar sus doctrinas dualistas de tipo sectario que los convertían en apolíticos "abstencionistas".

Parece existir, sin embargo, una tendencia, de parte de algún tipo pentecostal o neopentecostal, a conservar algo del espíritu "resistente al mundo", considerado como "pecador". Tendencia compartida en forma leve por adherentes de iglesias bíblicas y con reminiscencias milenaristas, como los mormones, testigos de Jehová y adventistas. Esta mayor distancia relativa del "mundo" lo es en ese caso del compromiso político partidario y también del compromiso cívico y ciudadano. 
En cuanto a los no creyentes y ateos, la evidencia muestra que hay tendencias que van en sentidos contrarios. Los jóvenes con mejor instrucción - quizás por su carácter de sujeto con mayor reflexividad - tienden a ser un poco más críticos del sistema político democrático y menos entusiastas con su sentido de responsabilidad ciudadana.

En general, sin embargo, y quizás porque en esa sumatoria pesan las viejas generaciones que se educaron en el ateísmo militante, que estaba generalmente asociado a posturas socialistas, que ahora vienen de retorno revalorizando la democracia, hay una mayor valoración de la ciudadanía democrática.

En todo caso hay núcleos duros de mayor participación en grupos religiosos, los "practicantes", sean católicos o de las diversas iglesias, y cultos que, por los datos a la mano, tienden a ser mucho más activos en las asociaciones de la sociedad civil tejiendo redes y capital social de forma bastante evidente. Incluso los que se sienten "más religiosos", lejos de inhibirse por un sentido espiritualista, son también los más dispuestos a comprometerse en responsabilidades ciudadanas e incluso políticas.

En otras palabras, la religión y su intensidad de creencia y práctica - generalmente asociada orgánicamente a alguna expresión eclesial - es garantía de construcción de ciudadanía democrática, y ésta en un sentido pluralista dado que en los tiempos que corren en todas las iglesias hay ahora expresiones de todas las ideologías y opciones del espectro político.

Los creyentes "a su manera" evidencian una toma de distancia respecto de las instituciones religiosas pero no sucede de forma similar respecto de las instituciones políticas: las formas democráticas de ciudadanía son preferidas por estos creyentes que evidencian un nivel mayor de reflexividad respecto de sus creencias recibidas de la tradición familiar. 
Nada conduce a pensar que el pluralismo religioso podría degenerar en una atomización de opciones y/o en una tendencia congregacionalista autosuficiente y cerrada: no hay tendencias sectarias notables (salvo leves tendencias en expresiones de religiones bíblicas).

Por otra parte, no hemos encontrado evidencia de tendencias fundamentalistas, salvo leves asociaciones entre grupos de protestantes y opciones autoritarias. Claro que ellas son muy minoritarias. Entre los evangélicos más bien hemos encontrado un amplio pluralismo en las opciones políticas de sus fieles. Igual cosa se observa en muchos casos latinoamericanos como el peruano, el brasileño y el mexicano (Vásquez, 2007; Campos Machado, 2006).

En todos los creyentes hemos encontrado una tendencia a participar en las asociaciones y a construir capital social en la sociedad y sólo en algunos grupos neopentecostales hemos encontrado tendencia a una participación comunitaria local, cerrada, y a evadir una participación política y social más amplia e inserta en el quehacer y debate nacional (Fediakova y Parker, 2006). Participación mucho más corporativa que en algunos casos ha dado origen a organizaciones políticas evangélicas que toman parte en procesos eleccionarios como en algunas elecciones de Perú, México, Brasil o Nicaragua (Biglieri, 1998).

Toda esta participación cívica coexiste con la pluralidad de creencias y prácticas religiosas. Mucha de esta diversidad religiosa existente se expresa en las múltiples manifestaciones de devociones y cultos populares, como la devoción a la Virgen de Guadalupe, el Umbanda, el Candomblé, la Santería y el Espiritismo, "Pare de Sufrir", el televangelismo, la Teología de Prosperidad, el Pentecostalismo, el Padre Rossi, La Madre Angélica y los "santos" populares como Sarita Colonia (Perú), Romualdito (Chile), María Lionza (Venezuela), el Gauchito Gil y la Difunta Correa (Argentina), la Santa Muerte (México), o las comunidades de base, los movimientos laicos, y las 
teologías de la liberación, para mencionar algunas de las expresiones más famosas. Algunas de estas manifestaciones religiosas están bajo el paraguas nominal de lo que el "catolicismo romano" a menudo ha denominado "el catolicismo popular", otros son expresiones de nuevos movimientos religiosos o cultos, muchos inspirados en la Nueva Era y en espiritualidades y esoterismos diversos, pero muchos de ellos son - en la mentalidad de los fieles - simplemente diferentes maneras de construir o reconstruir su propio significado religioso. Los niveles educativos formales superiores no están amenazando estos tipos de cultos pero están transformando las condiciones de producción de sentidos, posibilitando que el creyente reconstruya (y reforme), en su mentalidad y a su manera, el significado oficial y convencional que estas realidades han tenido para las iglesias institucionales o cultos o para la cosmovisión popular tradicional. Los creyentes más jóvenes están tomando distancia de las doctrinas oficiales e incluso de las viejas creencias y rituales populares y están recreando nuevos tipos de sincretismos en estilos que combinan muchos elementos simbólicos de diferentes, antiguas y nuevas tradiciones.

Sin embargo, la diversidad siempre ha sido parte del paisaje espiritual. Y las personas siempre han construido sus convicciones religiosas de forma personal y han creído en la intimidad de sus corazones, con la creatividad de que son capaces y las materias primas simbólicas (códigos, tradiciones, modelos, símbolos e idiomas) que encuentran a la mano. "Lo que es diferente hoy es que las iglesias cristianas tradicionales han perdido el poder para imponer su "ortodoxia" y para suprimir "las heterodoxias" de las personas" (Smith 2001).

El impacto alternativo producido por la pluralidad de opciones en el campo religioso, así como los cambios en la mentalidad religiosa, no apuntan necesariamente a opciones y compromisos políticos específicos y cerrados. Se debe recordar que el campo 
religioso tiene una relación compleja e indirecta con el campo político. De aquí que no se pueda deducir un aumento directo en el pluralismo político a causa del incremento del pluralismo religioso. Es necesario examinar cada caso nacional para determinar la relación mutua entre el campo religioso y político y su evolución futura.

La capacidad de la Iglesia católica y de las iglesias evangélicas de influir en el campo político depende de muchos factores incluso el arreglo de cada iglesia con el Estado, su propia fuerza institucional y su relación con la sociedad civil. En los contextos democráticos las opciones religiosas pluralistas estarán sujetas a formas diferentes de expresión, lo que reduce el impacto de los mensajes morales y sociales de la jerarquía.

La capacidad de movilizar la sociedad civil dependerá de la organización de base generada alrededor de las parroquias y las congregaciones pero incluso los fieles ya no obedecen dogmáticamente a sus pastores, como es de presumir.

El hecho es que las sociedades latinoamericanas tienen que tratar ahora con una Iglesia católica más débil en nuevos contextos culturales. Esta transformación del campo religioso latinoamericano - es decir, la influencia decreciente del catolicismo y el aumento del pluralismo religioso - es un desafío para la sociología y para las ciencias políticas ya que ellas tienen que analizar y evaluar estos cambios por lo que se refiere a los costos y beneficios para el desarrollo de la democracia (McCarthy, 1993).

El crecimiento del pluralismo religioso podría ser un síntoma del avance de la democracia. Pero lo será en la medida que las diversas corrientes religiosas promuevan una actitud ecuménica de tolerancia - incluso la tolerancia para las heterodoxias - y en la medida en que no caigan en la tentación de volver a doctrinas sectarias o perspectivas fundamentalistas. 
El pluralismo religioso crea más actores, voces y puntos de encuentro y va bajando las barreras de la organización eclesial y da acceso a la vida pública. Pero, al mismo tiempo, las nuevas reglas de juego de una sociedad civil más abierta y democrática retroalimentan a la religión, facilitando un mayor pluralismo (Levine, 2005). Como hemos dicho, es de esperar que las reformas y modernizaciones educativas también generen un factor de incremento de este pluralismo, y precisamente a mayores niveles educativos. Es de esperar un mayor nivel de participación en la construcción de la ciudadanía.

De esta manera la aparente tensión (Rubio y Rosales, 1995) ciudadanía/democracia universales vs el pluralismo de la diversidad, por una parte, y ciudadanía democrática como práctica pasiva de derechos y libertades políticas elementales vs ciudadanía activa que construye sociedad y movimientos cívicos, de otra parte, está al menos atenuada en las instancias de las organizaciones cívicas en las cuales los creyentes de las más variadas adhesiones y mucho más los creyentes practicantes que los otros asumen una participación activa con base en ideas, prácticas sociales, religiosas y políticas protagonistas de nuevos tejidos que van construyendo las nuevas formas de participación democrática en los países latinoamericanos.

Mainwaring y Torcal (2005) han estudiado el sistema de partidos en las democracias o semidemocracias de la "tercera ola democratizadora" en la post Guerra Fría. Los sistemas de partidos en países en vías de desarrollo como América Latina están menos institucionalizados, lo que explica una mayor distancia entre ciudadanos y partidos, menos influencia de las opciones ideológicas o los cleavage social (de tipo clase social, religión, etnia, nacionalidad, rural/urbano) y mayor influencia del personalismo, del clientelismo o de consideraciones de diverso tipo que explicarían la mayor "volatilidad" de los votantes y la mayor flexibilidad del 
sistema político, con posibilidades de recambios bruscos de líderes (carismáticos) y de los mismos partidos.

Las nuevas formas de adhesión religiosa pluralista en América Latina, tal como las hemos reseñado en su diversidad, en su complejidad y en sus explicaciones relativas a mentalidad, niveles de práctica religiosa y niveles de escolarización creciente, están en una lógica de mayor concordancia con el tipo de sistema democrático menos institucionalizado que describen Mainwaring y Torcal.

El adherente religioso, sea católico, católico "a su manera", evangélico pentecostal, adherente de una iglesia bíblica, o creyente "sin religión", adhiere a una concepción amplia de ciudadanía que no se reduce a los partidos políticos y que incluso cuestiona el accionar de éstos en la sociedad. Muchos de los nuevos creyentes, especialmente jóvenes con mayor instrucción escolar, tienen adhesiones menos institucionalizadas a las iglesias y cultos, por ende, menos sistemáticas y mucho más móviles y sus creencias aceptan sin cuestionamientos diversos grados de acomodos "sincréticos". Si bien el valor del sistema democrático está fuera de duda para la amplia mayoría, las adhesiones a partidos, opciones políticas y gobiernos son también menos sistemáticas, menos sometidas a una crítica ideológica o a una evaluación de efectos y susceptibles de mucho mayor "movilidad" incluso "volatilidad". Las opciones político-ideológicas de los jóvenes son, en este sentido, susceptibles de acomodos "sincréticos" (si se permite extrapolar esta expresión al campo ideológico), acomodos dictados por motivos pragmáticos, o de influencias personalistas o de tipo clientelar. Es decir, si el ciudadano medio latinoamericano está menos motivado en sus opciones de voto por influencias de tipo social, nacional o étnico, tampoco estará motivado por adhesiones religiosas. Sólo una minoría militante de algunas iglesias evangélicas y algunos cuantos católicos integristas estarán inclinados por opciones político-ideológicas concordantes con sus doctrinas morales y religiosas, pero la gran 
mayoría del electorado ya no incluye el factor religioso como contrapeso decisivo al momento de ejercer su derecho de voto.

El hombre latinoamericano religiosamente inspirado es un ciudadano activo. Construye tejido social y ciudadanía, aún cuando ello no garantiza, necesariamente, una mayor institucionalización del sistema de partidos, dada su distancia de los mismos.

Se trata de ciudadanos democráticos, pero no necesariamente legitimadores de sistemas de partidos fuertes. Sujetos de movilizaciones múltiples, pero más centrados en esferas vinculadas a redes sociales inmediatas o locales (familia, vecindario, comunidades) y no tanto en asociaciones funcionales (sindicatos y partidos). Se trata quizás de una "nueva ciudadanía" legitimada en opciones de origen religioso, pero secularizada. Ni temerosa de las "cosas del mundo", ni pretendidamente "sacralizante" del mundo. Nueva ciudadanía, amplia y poco política. Democrática, pluralista, que acepta las diversas opciones sociales y culturales. Una ciudadanía con todas las ventajas de ser portadora de un discurso y una práctica de construcción de una convivencia pacífica desideologizada, pero al mismo tiempo portadora de una desventaja que reside en el potencial de "apoliticismo relativo" (abiertos a los partidos pero críticos de ellos), el cual, en coyunturas críticas, puede ser susceptible de los vaivenes de procesos de participación muy inestables.

En cualquier circunstancia, como hemos visto, los practicantes, en una mayor proporción que los simples fieles, son partícipes de las redes de construcción de la sociedad civil y con ello afirman las bases de sustentación de un capital social que es un sano sustento a la construcción democrática de las sociedades latinoamericanas que miran hacia el futuro.

\section{Notas}

1 Este artículo recoge resultados parciales de la investigación Fondecyt n. 1060988, en que el autor es co-investigador con la Dra. Evguenia 
Fediakova a quien agradece esta colaboración. Sin embargo, la responsabilidad de lo afirmado en el presente artículo es exclusivamente del autor.

2 Hemos desarrollado más ampliamente este argumento en Cristián Parker G. (2008).

3 Sobre los procesos de reforma y modernización de la educación en América Latina, ver: Muñoz y Márquez, 2000; Álvarez, 2001; Arellano, 2002; Ricci, 2003; Torres y Schugurensky, 2004.

4 Muestras de Latinobarómetro: muestras probabilísticas trietápicas representativas del $100 \%$ de la población del país con N = 1000 a 1200 . Total de 18 países latinoamericanos representados: 10 de Sudamérica, 6 de Centroamérica, México y República Dominicana (Latinobarómetro, 2007).

5 Ver estudios de Fortuny Loret de Mola (1999) y de Cristina Gutiérrez Zúñiga y Renée de la Torre (2008) para México y del autor para Chile.

6 Ver datos del avance educacional en Mercosur, 2004, Unesco, 2005, UIS-OECD, 2006 y UIS (Unesco, Institute for Statistics), 2008.

7 Investigación Fondecyt n. 1060988, Muestra representativa preliminar de evangélicos de la Región Metropolitana y de la Región de la Araucanía $(\mathrm{N}=571)$.

\section{Religious pluralism, education and citizenship}

Abstract: This article describes the peculiar forms taken by religious change in Chile. It considers the adhesion to new religious movements and beliefs as well as education and its interference on the multiplication of religious institutions. It also pictures the concrete manifestations of religious change and their consequences for political culture.

Key words: religious change; religious pluralization; religious beliefs; Chile. 


\section{Bibliografía}

ÁLVAREZ GALLEGO, Alejandro. Del estado docente a la sociedad educadora: ¿un cambio de época? Revista Iberoamericana de Educación, OEI, n. 26, mayo/ago. 2001. Disponible en: $<$ http://www.rieoei. org/rie26f.htm>.

ARELLANO MARÍN, José Pablo. Competitividad internacional y educación en los países de América Latina y el Caribe. Revista Iberoamericana de Educación, OEI, n. 30, sept./dic. 2002. Disponible en: $<$ http://www.campus-oei.org/revista/rie30f.htm>.

BIGLIERI, Paula. "Ciudadanos de la fe: práctica religiosa y conducta cívica en grupos pentecostales" (ponencia en Primeras Jornadas de Teoría y Filosofía Política, Universidad de Buenos Aires, Facultad de Ciencias Sociales, 1998), en Colección Filopol, Clacso. Disponible en: $<$ http://www.clacso.org/wwwclacso/espanol/html/biblioteca/fbiblioteca.html>.

CAMPOS MACHADO, Maria das Dores. Política e religião: a participação dos evangélicos nas eleições. Rio de Janeiro: FGV, 2006.

CARVAJAL, Patricio. El derecho de resistencia en la teología política de Juan Calvino. Revista de Estudios Histórico-Jurídicos, n. 22, p. 335-351, 2000.

DEBRAY, Regis. El arcaísmo postmoderno. Buenos Aires: Manantial, 1996.

DE LA TORRE, Renée; GUTIÉRREZ ZÚÑIGA, Cristina (Coords.). Atlas de la diversidad religiosa en México. México: Centro de Investigaciones y Estudios Superiores en Antropología Social (Ciesas): Universidad de Quintana Roo (UQRO): Colegio de la Frontera Norte (Colef): El Colegio de Jalisco (Elcoljal): Colegio de Michoacán (Colmich): Subsecretaría de Asuntos Religiosos de la Secretaría de Gobernación (Segob), 2007.

FEDIAKOVA, Evguenia; PARKER G., Cristián. Evangélicos chilenos: ¿apolíticos o nuevos ciudadanos? Revista Si Somos Americanos, v. VIII, n. 1, p. 115- 131, 2006. 
FORTUNY LORET DE MOLA, Patricia (Coord.). Creyentes y creencias en Guadalajara. México D.F.: Consejo Nacional de la Cultura y las Artes (Conaculta): Instituto Nacional de Antropología e Historia (Inah): Centro de Investigaciones y Estudios Superiores en Antropología Social (Ciesas), 1999.

FORNI, Floreal; FORTUNATO MALLIMACI, Luis Cárdenas (Coords.) Guía de la diversidad religiosa de Buenos Aires. Buenos Aires: Biblos, 2003.

FRESTON, Paul. Popular protestants in Brazilian politics: a novel turn in sect-state relations. Social Compass, n. 41, 4, p. 537-570, 1994.

GONZÁLEZ, Sergio. Representación social de la noción de ciudadanía: construcción y ampliación de la ciudadanía en grupos articulados al sistema educacional. 2001. Tesis (Doctorado en Psicología) - Facultad de Ciencias Sociales, Escuela de PostGrado, Universidad de Chile.

GUTIÉRREZ ZÚÑIGA, Cristina; DE LA TORRE, Renée. "La exploración de imaginarios creyentes en Jalisco: un análisis de dos encuestas" (ponencia en XI Encuentro de la Red de Investigadores del Fenómeno Religioso en México, Universidad de Quintana Roo), Quintana Roo, México, 17-19 abr. 2008.

INSTITUTO NACIONAL DE ESTADÍSTICAS (INE). Censo 2002: síntesis de resultados. Santiago: INE, 2003.

INSTITUTO NACIONAL DE LA JUVENTUD (Injuv). Quinta encuesta nacional de juventud. Santiago: Injuv, 2007.

. Resultados preliminares cuarta encuesta nacional de juventud 2003. Santiago: Injuv, 2004.

. Segunda encuesta nacional de juventud. Los jóvenes de los noventa: el rostro de los nuevos ciudadanos. Santiago: Injuv, 1999.

. Tercera encuesta nacional de juventud. Santiago: Injuv, 2001. 
INGLEHART, Ronald; BAKER, Wayne E. Modernization, cultural change, and the persistence of traditional values. American Sociological Review, n. 65, p. 19-51, Feb. 2000.

KYMLICKA, Will. Ciudadanía multicultural: una teoría liberal de los derechos de las minorías. Barcelona: Paidós, 1996.

; WAYNE, Norman. Return of the citizen: a survey of recent work on citizenship theory. Ethics, n. 104, p. 257-289, Jan. 1994.

LAGOS, Humberto. Crisis de la esperanza: religión y autoritarismo en Chile. Santiago: Presor-Lar, 1988.

LALIVE D’EPINAY, Christian. El refugio de las masas. Santiago: Ed. del Pacífico, 1968.

. Religion, dynamique sociale et dépendence. Paris: Mouton, 1975.

LAMBERT, Yves. Young people confound the European religious exception (en ISSR, Religion and Generations, XXVII Conference, 21-25 jul. 2003), Turín, 2003.

LATINOBARÓMETRO. Informe Latinobarómetro 2007. Banco de Datos en Línea, Santiago de Chile, Corporación Latinobarómetro. Disponible en: $<$ http://www.latinobarometro.org $>$.

LEVINE, Daniel H. Pluralidad, pluralismo y la creación de un vocabulario de derechos. América Latina Hoy, 41, p. 17-34, dic. 2005.

MAINWARING, Scott; TORCAL, Mariano. La institucionalización de los sistemas de partidos y la teoría de los sistemas partidistas después de la tercera ola democratizadora. América Latina Hoy, 41, p. 141173, dic. 2005.

MARSHALL, T. H. (1998) Ciudadanía y clase social. En:

BOTTOMORE, T. Ciudadanía y clase social. Madrid: Alianza, 1998, p. 15-82.

; BOTTOMORE, T. Ciudadanía y clase social. Madrid: Alianza, 1998. 
MARTIN, David. Tongues of fire: the explosion of Protestantism in Latin America. Oxford: Blackwell, 1990.

McCARTHY, John. Religion, democratization, and market transition (workshop sponsored by the NSF, Sociology Program, Washington, D.C., 6-7 Dec. 1993).

MERCOSUR. "Indicadores estadísticos del Sistema Educativo del Mercosur 2004. Disponible en: <http://www.sic.inep.gov.br/index. php?option $=$ com_content $\&$ task $=$ blogcategory\&id $=21 \&$ Itemid $=39$ \&lang $=\mathrm{br}>$.

MUÑOZ IZQUIERDO, Carlos; MÁRQUEZ JIMÉNEZ, Alejandro. Indicadores del desarrollo educativo en América Latina y de su impacto en los niveles de vida de la población. Revista Electrónica de Investigación Educativa, n. 2, 2, 2000. Disponible en: $<$ http://redie.uabc. $\mathrm{mx} /$ vol2no2/contenido-munoz.html $>$.

NYE, Jr., Joseph. Soft power. Foreign Policy, n. 80, p. 153-171, otoño 1990.

PARKER G., Cristián. ¿América Latina ya no es católica? Pluralismo Cultural y Religioso Creciente. América Latina Hoy, n. 41, p. 35-56, dic. 2005.

. "Cultural and religious pluralism and challenges of cultural institutions in societies within a process of globalization" (ponencia en workshop Contemporary Challenges to Catholicism in Latin America, Kellogg Institute), South Bend, Indiana: University of Notre Dame, 2-3 Oct. 2003.

. Education and increasing religious pluralism in Latin America: the case of Chile. En: HAGOPIAN, Frances (Ed.). Religious pluralism, democracy, and the Catholic Church in Latin America: social change, religion, and politics in the twenty-first century. South Bend, Indiana: University of Notre Dame Press, Notre Dame Indiana, 2008 (en prensa).

. Estudio sobre cambios culturales en jóvenes secundarios (Investigación del autor, 2000). 
PARKER G., Cristián. Estudio sobre evangélicos en Chile democrático (1990-2005): ¿formación de la nueva ciudadanía?. Proyecto Fondecyt n. 1060988. (Investigadora principal: Dra. Evguenia Fediakova; co-investigador: Cristián Parker G. En curso.)

. Estudio sobre orientación hacia la ciencia y la innovación, y orientación cívica, en estudiantes universitarios chilenos, 2005. Proyecto Fondecyt n. 1040261.

. Las iglesias y su acción social en Chile. Santiago: Ed. UnicefAcademia, 1996.

. Los jóvenes chilenos: cambios culturales; perspectivas para el siglo XXI. Santiago: Mideplan, UEP, 2000.

. "Universitarios, ciencia, tecnología y conciencia". Informe final, Proyecto Fondecyt n. 1040261. Santiago: Instituto de Estudios Avanzados, Universidad de Santiago de Chile, 2007.

; PEÑA, Luís. “Aceptación en la población de la Región Metropolitana de medidas alternativas a la reclusión" (Segundo Simposio Nacional de Investigación sobre Violencia y Delincuencia, Fundación Paz Ciudadana e Instituto de Sociología, Universidad Católica de Chile), Santiago, p. 247-268, 2005. (Datos religiosos disponibles con Parker.)

; BARRÍA, Rodolfo. "Perfil de los estudiantes de la Universidad de Santiago de Chile y sus valores". Informe de investigación, Universidad de Santiago de Chile, Santiago, dic. 2002 (publicación interna).

; VIDAL, Erick. "Religiosidad en la familia católica chilena". Informe final, Proyecto Familia y Religión, Santiago, Conferencia Episcopal de Chile (Cech): Centro de Estudios de la Realidad Contemporánea (Cerc): Universidad Academia de Humanismo Cristiano (UAHC), Santiago, mayo 2007.

PIERUCCI, Antônio Flavio; PRANDI, Reginaldo (Eds.). A realidade social das religiões no Brasil: religião, sociedade e política. São Paulo: Hucitec, 1996. 
RICCI, Rudá. Vinte anos de reformas educacionais. Revista Iberoamericana de Educación, n. 31, ene./abr. 2003. Disponible en: <http:// www.campus-oei.org/revista/rie31f.htm>.

RUBIO CARIACEDO, J.; ROSALES, J. M. El nuevo pluralismo y la ciudadanía compleja. Revista Sistema, n. 122, p. 53-62, 1995.

SHAFIR, Gershon. Introduction: the evolving tradition of citizenship. En: ZAFIRO, Gershon (Ed.). The citizenship debates: a reader. Minneapolis: University of Minnesota Press, ch. 1, p. 1-28, 1998.

SMITH, Brian. The church and politics in Chile. Princeton: Princeton University Press, 1982.

SMITH, Dennis A. "Religion and the electronic media in Latin America: a review" (ponencia en Meeting of the Latin American Studies Association, Washington, D.C., 6-8 Sept. 2001).

STOLL, David. Is Latin America turning protestant? Berkeley: University of California Press, 1990.

TABIN, Jean Pierre. "Immigrants and integration" (ponencia en The Year 2000 International Research Conference on Social Security, Helsinki, 25-27 Sept. 2000.

TEIXEIRA, Faustino; MENEZES, Renata (Orgs.). As religiões no Brasil: continuidades e rupturas. Petrópolis: Vozes, 2006.

TORRES, Carlos Alberto; SCHUGURENSKY, Daniel. The political economy of higher education in the era of neoliberal globalization: Latin America in comparative perspective. En: CANNINO, Maria J.; TORRES-SAILLANT, Silvio (Eds.). The challenges of public higher education in the Hispanic Caribbean. Princeton, NJ: Markus Wiener Publishers, 2004, p. 21-45.

TROELTSCH, Ernest. The social teaching of the Christian churches. New York: George Allen and Unwin Ltd., 1931.

TURNER, Bryan S. Global sociology and the nature of rights. Societies Without Borders, v. 1, n. 1, p. 41-52, 2006. 
UNESCO INSTITUTE FOR STATISTICS (UIS). (2008) Available at: $<$ http://stats.uis.unesco.org $>$.

/ORGANIZAÇÃO PARA A COOPERAÇÃO ECONÔMICA E O DESENVOLVIMENTO (UIS/OECD). World Education Indicators, 2006. Available at: <http://www.uis.unesco.org/ev.php?URL_ ID $=5263 \&$ URL_DO=DO_TOPIC\&URL_SECTION $=201>$.

UNITED NATIONS ORGANIZATION FOR EDUCATION, SCIENCE AND CULTURE/EDUCATION FOR ALL (Unesco/EFA). EFA Global Monitoring Report 2005. Available at: $<$ http://portal.unesco.org/education/en/ev.php-URL_ID $=35939 \& U R L \_D O=D O$ TOPIC\&URL_SECTION=201.html $>$.

VÁSQUEZ PALACIOS, Felipe. La fe y la ciudadanía en la práctica evangélica veracruzana. México, D.F: Publicaciones de la Casa Chata: Centro de Investigaciones y Estudios Superiores en Antropología Social (Ciesas), 2007.

WEBER, Max. Citizenship in ancient and medieval cities. En: ZAFIRO, Gershon (Ed.). The citizenship debates: a reader. Minneapolis: University of Minnesota Press, ch. 3, p. 43-52, 1998.

. La ética protestante y el espíritu del capitalismo. Barcelona: Península, 1969. 